\title{
Effective Solder for Improved Thermo-Mechanical Reliability of Solder Joints in a Ball Grid Array (BGA) Soldered on Printed Circuit Board (PCB)
}

\author{
JOSHUA A. DEPIVER (1), ${ }^{1,3}$ SABUJ MALLIK, ${ }^{1,4}$ and EMEKA H. AMALU ${ }^{2,5}$ \\ 1.-School of Mechanical Engineering and the Built Environment, College of Engineering and \\ Technology, University of Derby, Markeaton Street, Derby DE22 3AW, UK. 2.-Department of \\ Engineering, School of Computing, Engineering and Digital Technologies, Teesside University, \\ Middlesbrough, Tees Valley TS1 3BA, UK. 3.-e-mail: j.depiver@derby.ac.uk. 4.-e-mail: \\ s.mallik@derby.ac.uk. 5.—e-mail: E.Amalu@tees.ac.uk
}

Ball grid array (BGA) packages have increasing applications in mobile phones, disk drives, LC displays and automotive engine controllers. However, the thermo-mechanical reliability of the BGA solder joints challenges the device functionality amidst component and system miniaturisation as well as wider adoption of lead-free solders. This investigation determines the effective BGA solders for improved thermo-mechanical reliability of the devices. It utilised a conducted study on creep response of a lead-based eutectic $\mathrm{Sn} 63 \mathrm{~Pb} 37$ and four lead-free Tin-Silver-Copper (SnAgCu) [SAC305, SAC387, SAC396 and SAC405] solders subjected to thermal cycling loadings and isothermal ageing. The solders form the joints between the BGAs and printed circuit boards (PCBs). ANSYS R19.0 package is used to simulate isothermal ageing of some of the assemblies at $-40^{\circ} \mathrm{C}, 25^{\circ} \mathrm{C}, 75^{\circ} \mathrm{C}$ and $150^{\circ} \mathrm{C}$ for 45 days and model the thermal cycling history of the other assemblies from $22^{\circ} \mathrm{C}$ ambient temperature for six cycles. The response of the solders is simulated using the Garofalo-Arrhenius creep model. Under thermal ageing, SAC396 solder joints demonstrate possession of least strain energy density, deformation and von Mises stress in comparison to the other solders. Under thermal cycle loading conditions, SAC405 acquired the lowest amount of the damage parameters in comparison. Lead-free SAC405 and SAC387 joints accumulated the lowest and highest energy dissipation per cycle, respectively. It is concluded that SAC405 and SAC396 are the most effective solders for BGA in devices experiencing isothermal ageing and temperature cycling during operation, respectively. They are proposed as the suitable replacement of eutectic Sn63Pb37 solder for the various conditions.

Key words: Ball grid array (BGA), thermal cycling, isothermal ageing, strain rate, stress, strain energy density

\section{INTRODUCTION}

Ensuring reliability of solder joints in electronic devices is vital for the operational performance of electronics systems used in safety-critical applications such as aerospace, defence, oil and gas

(Received May 10, 2020; accepted September 25, 2020; published online November 5, 2020) drilling, automobiles, medical devices, and power grids. Solder joints have a significant function by providing mechanical, electrical and thermal connections between the electronics package and printed circuit board (PCB). As the solder joint is both brittle and miniature, it is the weakest part of any electronic assembly and thus sensitive to premature damage. Increasing miniaturisation of electronic components and recent application in hightemperature ambient have put higher demand on 
thermo-mechanical reliability of solder joints in these components. The capability of solder joints to remain in conformance with their mechanical, electrical and visual specifications over a specified duration, under a specific set of operational provisions is referred to as solder joint reliability. The reliability of solder joints is assessed by many parameters which include shear strength, creep resistance, drop shock, thermal fatigue and vibration resistance. Owing to the adoption of the Restriction of Hazardous Substances (RoHS) directives on 1st July 2006, by the European Union (EU), there has been new progress and developments in lead-free solders as a replacement for the conventional lead-based solders for application in the electronics manufacturing industries. ${ }^{1-4}$ Amongst the lead-free solders investigated, Sn-Ag- and Sn$\mathrm{Ag}-\mathrm{Cu}$ (SAC)-based solders offer the most promising characteristics as replacement of lead-based solders. ${ }^{5,6}$ The introduction of several lead-free solders added new dimension to reliability issues in the electronic devices. The properties and responses to the various loading conditions arising from diverse environments the new solders in electronic devices operate are yet to be fully qualified. Consequently, mission critical systems are yet to be fully compliant to the directives and necessitates continued effort in this regard.

Several factors influence solder joint reliability and drastically reduces the lifetime of the joint. Recognising these factors and mitigating their effect during the design and manufacturing phases can significantly reduce expensive and difficult-to-solve situation in the device life cycle. Electronic device loading during field operations can be modelled using thermal cycling and isothermal ageing. Thermal ageing of solder joints produces changes in solder microstructure which triggers creep failure. ${ }^{7,8}$ Knowledge and understanding of the failure of these systems are essential in preventing the untimely failure of the devices. ${ }^{9}$ Temperature cycling produces thermal stress in the solder joints, which culminates in fatigue failure. Solder alloys are often used in electronic packaging because they have low melting temperature and excellent wetting properties. During electronic devices service life, a mismatch of coefficient of thermal expansion (CTE) of different materials bonded together in the assembly causes cycling stresses and strain in their solder joints. The solder joints also deteriorate owing to creep response which in turn depends on temperature, ageing, stress, strain and solder grain size. The response is modelled using a variety of creep relations based on the Garofalo model. Constitutive models employed for solder alloys have been reported by Basaran et al. ${ }^{10}$ and Gomez and Basaran. ${ }^{11}$ An analysis of the models shows that the creep behaviour of a solder alloy significantly depends on age, stress, and temperature and solder grain size. Fatigue is dominant during cycling between the extremes which is why creep is the dominant mechanism during the dwelling period and at high temperature.

Barbini and Meilunas ${ }^{12}$ investigated the reliability of Pb-free LGAs and BGAs: effects of solder joint size, cyclic strain and microstructure. The researchers conducted an accelerated thermal cycle (ATC) experiment analysing similarly assembled area array devices signifying land grid array (LGA) and ball grid array (BGA) technology with $0.254 \mathrm{~mm}$, $0.30 \mathrm{~mm}$, and $0.40 \mathrm{~mm}$ pitch diameter SAC305 solder balls. The components were subjected to three thermal cycle conditions to promote 2 nd level solder fatigue. Failure data obtained were examined by employing Weibull examinations. The outcomes reveal that time to failure is profoundly impacted by the package thermal cycle temperatures and pitch in a method predicted by simplistic mechanics. In the conclusion of their work, a strain rate approach for analysing the ATC reliability data seems to explain the effects than a strain range method adequately. By utilising the strain rate procedure, it has been shown that SAC305 solder joints approximating LGA-like joint qualities (shape, height and microstructure) can be more reliable than more substantial BGA-like SAC305 solder joints for an assigned strain rate. ATC test temperatures have a meaningful influence on solder joint lifetime. The $-40 / 125^{\circ} \mathrm{C}$ thermal cycle is significantly more damaging than the $-20 / 100^{\circ} \mathrm{C}$ and $0 / 100^{\circ} \mathrm{C}$ thermal cycle in addition to the same cyclic strain rate. The $-20 / 100^{\circ} \mathrm{C}$ and $0 / 100^{\circ} \mathrm{C}$ thermal cycle give comparable results, particularly when comparing related cyclic strain rates.

Creep plays a crucial role in the damage mechanism of solder joints subjected to thermo-mechanical loading. Thus, considering creep damage is vital in the design of a reliable electronic circuit board assembly. Ramachandran et al. $^{13}$ examined an overview of solder joint reliability due to creep deformation, and Ramachandran and Chiang ${ }^{14}$ investigated the feasibility evaluation of creep model for failure assessment of solder joint reliability of wafer-level packaging. They developed a new creep model based on the assumptions that an instantaneous steady-state creep form eliminates the evolution term, resulting in a creep equation with four parameters and the proposed model has a similar vital statement similar to that of the wellknown hyperbolic sine model. The model considerably broadens the application of the hyperbolic model. They used a wafer level chip scale package (WLCSP) on PCB and performed thermal cycling experiments in ESPEC TCC-150. The steady-state creep is the dominant deformation experienced by solder alloys. This can be quantitatively estimated, and a series of constitutive models were proposed. The two models that are widely accepted for the characterisation of solder alloys by considering the diffusion-controlled creep deformation mechanism are reported by Pang et al. ${ }^{15}$ Isotropic elastic model and creep model was considered for the soldered 
material because this model plays an important role in the failure/damage of solders interconnects under thermo-mechanical loading conditions and creep damage. Because the failure of the entire electronic packaging is often induced by the failure of solders, modelling and simulation of solder joint performance are quite significant in ensuring the quality and reliability of electronic products.

Several creep constitutive models have been reported. The Garofalo-Arrhenius constitutive relation was used for this model because it exhibits a lower estimated variance of error terms than the Dorn model. ${ }^{13,16-23}$ Although this model ignores grain size, diffusivity and other parameters, getting suitable material parameters for investigated SAC solder alloy materials is not readily available. Lee and Basaran ${ }^{24}$ studied a creep model for solder alloys. In their work, they proposed several creep models, and it is shown that while two creep models may describe the same material stress-strain curves well, they may yield different results when used for cyclic loading. They observed that the stress exponent, $n$, depends on grain size. In order to account for temperature dependency on diffusivity, Arrhenius's law is used with a popular creep equation called the Dorn equation, which was improved by including a hyperbolic-sine term. The report of their analysis affirms that the hyperbolic sine model presents a more suitable representation on the whole study compared to a power law for solder alloys and that several other models were successful in fitting experimental data which are performed using only two empirical data sets and only uses a lead-based eutectic $\mathrm{Sn} 63 \mathrm{~Pb} 37$ solder alloy. An important goal of the constitutive equation is to describe various microstructural processes, through its parameters, involved in deformation that may lead to the steady-state and rupture of the material. Garofalo Arrhenius constitutive equations mathematically describe the deformation behaviour of materials as a function of the strain, strain rate and temperature. ${ }^{25-27}$ The creep strain rate can be a function of stress, strain, and temperature. When a material is subjected to constant stress with an increase in the strain rate, this is referred to as the creep effect. In other words, creep is a time-dependent deformation in a material. Fahim et al. ${ }^{28}$ investigated high-temperature creep response of lead-free solders. In their work, they characterised the high temperature creep behaviours of SAC405 and concluded that SAC alloys were more resistant to creep at high temperature.

Creep deformation has become a dominant deformation in electronics devices and happens when $T_{H}=T / T_{m}$ exceeds $\sim 0.4$ and also occurs at reasonably low temperatures. ${ }^{29}$ Creep effect is more critical in metallic material at high homogeneous temperature. Amalu and Ekere ${ }^{30}$ studied the modelling evaluation of Garofalo-Arrhenius creep relation for lead-free solder joints in surface mount electronic component assemblies. They used different creep parameters in Garofalo-Arrhenius constitutive creep relation and used four sets of values, proposed by Lau, ${ }^{29}$ Pang et al., ${ }^{31}$ Schubert et al. $^{32}$ and Zhang et al. ${ }^{33}$ to generate four hyperbolic sine creep relations and proposed a paradigm to select suitable constitutive model(s) for accurate prediction whilst suggesting the development of new solder constitutive relations. The Garofalo creep constitutive constants used in the FEA simulation are presented in Table V. The scope of this investigation did not study grain size, diffusivity or other creep parameters because our analysis and comparisons are based on FEA simulation. An essential component of BGA electronic package reliability is the stability and durability of solder joints. This failure mechanism could be fatigue due to plastic deformation in response to cyclic creep, strain rate, strain energy density, stress relaxation, applied mechanical stresses, fracture of brittle intermetallic compounds or a combination. A solder joint in a package that has failed may be surrounded by solder joints that have not yet failed or ruptured.

The generally used solder-joint failure criteria include those based on plastic strain, ${ }^{34-37}$ creep strain, ${ }^{38-41}$ inelastic work, ${ }^{42,43}$ classic fracture mechanics, ${ }^{44}$ and fracture-calibrated energy. ${ }^{45}$ Each failure criterion requires specific material properties and may place the requirements on the nature of the numerical solution obtained either by calculation or an FEA simulation. For this research, the failure criterion used creep strain and inelastic work for five solder joint alloy materials (lead-based eutectic Sn63Pb37, and lead-free SnAgCu: SAC305, SAC387, SAC396 and SAC405). Consequently, the solder joint ruptured surfaces often advance to make compressively loaded contact after cracking. As a result of thermal changes, cyclic plastic strain and shear stress is the primary type of stress-strain induced on the solder joints. Because of this premise, the rough fracture surfaces of failed solder joints slide relative to one another during accelerated thermal cycling, producing electrical transients that are characteristic of the short term. ${ }^{46-50}$ Failures are defined based on the increase in resistance, ${ }^{41,51-57}$ resistance thresholds, or electrical discontinuities. ${ }^{12,58-62}$ Four standards are currently in use by the electronics manufacturing industry to specify solder joint failure criteria during reliability and qualification tests of surface mount technology (SMT) solder joints. These are IPC-SM-785, ${ }^{63}$ IPC$9701,{ }^{64,65} \mathrm{JESD}_{22-B 111,{ }^{66} \text { and IPC/JEDEC-9702. }}{ }^{67}$ Electronics manufacturing companies have generally adopted these test standards or customized their standards.

- IPC-970164,65 describes failure standards based on the measurement method selected. It is noted in the standard that is irregularly measuring resistance, using probes is not a satisfactory option for continuous monitoring of an electrical 
daisy chain. The failure criteria advised in IPC/ JEDEC-9702 ${ }^{67}$ for monotonic bend characterization of board-level also interconnects a $20 \%$ increase in daisy-chain net resistance.

- IPC-SM-785 ${ }^{63}$ recommends continuous monitoring of daisy-chain continuity test loops to detect a failure. The standard states the polling interval should be $2 \mathrm{~s}$ or less.

- JESD22-B111 ${ }^{66}$ stipulates that the solder joint failure criteria for board-level drop tests.

- Comparable to IPC-SM-785, IPC-9701 and IPC/ JEDEC-9702, JESD22-B111 stipulates in situ electrical monitoring of daisy chain nets for failure through each drop. It asserts that the electrical continuity of all nets should either be detected by a high-speed data acquisition system or event detector.

Qi et al. ${ }^{49}$ have achieved similar reviews. In a sense, all of these criteria are subjective because, at this time, the relationship between the crack area of interconnection and the change in resistance of the interconnection has not been established. This definition of failure differs from the three IPC standards discussed earlier due to drop test characteristics. In addition to the electrical discontinuity aspect, this standard also points out that a visible separation of the component from the test board, even without a significant increase in resistance or intermittent discontinuity, is also considered a failure. Several studies have investigated various solder joint alloy materials reliability issues in electronic devices. These include portable electronic devices (PEDs) in the consumer electronics sector and high-reliability military hardware as well as under the hood of an automobile, but no studies have compared and benchmarked the five solder joint alloys (lead-based eutectic $\mathrm{Sn} 63 \mathrm{~Pb} 37$ and lead-free SnAgCu: SAC305, SAC387, SAC396 and SAC405) considered in this work. These lead-free alloys are predominantly used in the assembly of these devices. In the current ever miniaturisation manufacturing trend in electronics packaging amidst increasing functionality, the identification and knowledge of an effective lead-free solder and its adoption in electronics manufacturing will increase the reliability of the electronic devices. This proposition necessitates this research and informs the need for the comparison.

The research aims to propose an effective solder for improved thermo-mechanical reliability of solder joints in the ball grid array (BGA) package soldered on printed circuit boards (PCB). The objectives of the research are as follows:

- Study creep response of solder joints of leadbased eutectic Sn63Pb37 and four key lead-free tin-silver-copper ( $\mathrm{SnAgCu}$ ) solders subjected to thermal cycling loadings.

- Study creep response of lead-based eutectic $\mathrm{Sn} 63 \mathrm{~Pb} 37$ and four key lead-free tin-silver- copper ( $\mathrm{SnAgCu}$ ) solders subjected to isothermal ageing.

- Simulate, using Garofalo-Arrhenius creep model, the responses of the solder joints in the systems above and obtain the magnitude of stress, strain, strain energy density and deformation in the joints.

- Advise, based on the results obtained from the investigations above, on effective lead-free solder which will be a suitable replacement of leadbased eutectic $\mathrm{Sn} 63 \mathrm{~Pb} 37$ solder for the various conditions studied.

\section{MATERIALS AND METHODS}

\section{Materials Used in the FEA Simulation Studies}

$\mathrm{Sn}-\mathrm{Pb}$ solder alloys have been used extensively in electronics applications for over 30 years until legislation covering the environmental effects of lead $(\mathrm{Pb})$ in electronics assembly was introduced on 1st July 2006. The tin-silver-copper ( $\mathrm{SnAgCu})$ alloy combination is one of the most commonly used leadfree solder alloy materials. The selection of the solder alloy depends on one or more of the factors listed below. ${ }^{68}$

- Wettability on substrate.

- Temperature capability, consideration for process and service temperature.

- Service and environmental compatibility.

- Metallurgical compatibility, consideration of potential formation of intermetallic compounds (IMC).

\section{Lead-Based Eutectic Sn63Pb37}

The lead-based eutectic $\mathrm{Sn} 63 \mathrm{~Pb} 37$ is an alloy with liquidus $183^{\circ} \mathrm{C}\left(361^{\circ} \mathrm{F}\right)$, high purity, low dross, and complies with IPC J-STD-006. The physical and mechanical properties of lead-based eutectic $\mathrm{Sn} 63 \mathrm{~Pb} 37$ is presented in Table I. The lead-based eutectic $\mathrm{Sn} 63 \mathrm{~Pb} 37$ is corrosion resistant with a very good electrical property. They also create solder interconnects with excellent mechanical strength suitable for electronic devices.

\section{Sn96.5Ag3.0Cu0.5 (SAC305)}

SAC305 is a lead-free solder alloy that contains $96.5 \%$ tin, $3.0 \%$ silver, and $0.5 \%$ copper. This solder alloy material falls under the Japan Electronics Industries Development Association (JEIDA) recommendation for lead-free soldering. The solder alloy has several benefits such as lowest cost $\mathrm{SnAgCu}$ alloy, excellent fatigue resistance, compatibility with all flux types, excellent solder joint reliability and best wetting SAC alloy. The physical and mechanical properties of SAC305 are presented in Table I. 
Table I. Physical and mechanical properties of solder alloys ${ }^{69,70}$

\begin{tabular}{|c|c|c|c|c|c|c|c|}
\hline $\begin{array}{l}\text { Solder } \\
\text { Alloy }\end{array}$ & $\begin{array}{l}\text { Melting } \\
\text { Point, }{ }^{\circ} \text { C So- } \\
\text { lidus/Liq- } \\
\text { uidus }\end{array}$ & $\begin{array}{c}\text { Density, } \\
\text { g/ } / \mathbf{c m}^{3}\end{array}$ & $\begin{array}{c}\text { Electrical } \\
\text { Resistivity, } \\
\mu \Omega . \mathbf{m}\end{array}$ & $\begin{array}{c}\text { Thermal Con- } \\
\text { ductivity, W/ } \\
\text { m.K }\end{array}$ & $\begin{array}{c}\text { Tensile } \\
\text { Strength at } \\
\text { Break, } \\
\text { kgf } / \mathbf{c m}^{2}\end{array}$ & $\begin{array}{c}\text { Tensile } \\
\text { Elongation } \\
\text { at Break, \% }\end{array}$ & $\begin{array}{c}\text { Brinell } \\
\text { Hardness, } \\
\text { HB }\end{array}$ \\
\hline \multicolumn{8}{|c|}{ Alloys of tin (Sn) and lead (Pb) with and without silver (Ag) } \\
\hline Sn63Pb37 & $183 / 183$ & 8.40 & 0.145 & 50 & 525 & 37 & 17 \\
\hline \multicolumn{8}{|c|}{ Alloys of tin (Sn) with silver (Ag) and/or copper (Cu) } \\
\hline SAC305 & $217 / 220$ & 7.38 & 0.132 & 58 & 500 & 19 & 15 \\
\hline SAC405 & $217 / 220$ & 7.44 & 0.132 & 62 & 530 & 17 & 15 \\
\hline SAC387 & $217 / 220$ & 7.44 & 0.132 & 60 & 600 & 16 & 15 \\
\hline SAC396 & $217 / 221$ & 7.46 & 0.132 & 61 & 550 & 18 & 15 \\
\hline
\end{tabular}

\section{Sn95.5Ag4.0Cu0.5 (SAC405)}

SAC405 solder alloy is lead-free tin/silver/copper that contains $95.5 \%$ tin $(\mathrm{Sn}), 4.0 \%$ silver $(\mathrm{Ag})$ and $0.5 \%$ copper $(\mathrm{Cu})$ often written as Sn95.5Ag4.0Cu0.5. The SAC405 solder is more expensive than SAC305 and is used by electronics manufacturing companies working with PBGA, CBGA, LBGA, CSP and BGA. The physical and mechanical properties of SAC405 are presented in Table I.

\section{Sn96.5Ag3.8Cu0.7 (SAC387)}

SAC387 solder alloy is a lead-free tin/silver/copper $\mathrm{Sn} 95.5 \mathrm{Ag} 3.8 \mathrm{Cu} 0.7$ solder alloy material for BGA and CSP electronics components used by electronics and electrical manufacturing companies. The leadfree tin/silver/copper contains $95.5 \%$ tin (Sn), 3.8\% silver $(\mathrm{Ag})$ and $0.7 \%$ copper $(\mathrm{Cu})$. The physical and mechanical properties of SAC387 are presented in Table I.

\section{Sn96.5Ag3.9Cu0.6 (SAC396)}

SAC396 solder is a lead-free tin/silver/copper alloy that contains $95.5 \%$ tin ( $\mathrm{Sn}), 3.9 \%$ silver $(\mathrm{Ag})$, and $0.6 \%$ copper $(\mathrm{Cu})$ and it is often written as Sn95.5Ag3.9Cu0.6 solder. It has features which include excellent fatigue resistance, excellent solder joint reliability, best wetting SAC alloy and compatibility with all flux types. The physical and mechanical properties of SAC4396 are presented in Table I.

\section{Copper (Cu) Pads}

There are generally two types of pad design, which are soldermask- and copper-defined pads. Some merits of the copper-defined pad are that it is to easier design traces because the pad size is relatively small, one can more precisely control the position and size of the pad, and it has very good solderability. The drawbacks are that the copper foil can be torn due to external forces, and as a result of the miniature nature of the pad, the strength of the pad attached to the circuit board is relatively low. For the soldermask-defined pad (SMD), some advantages are that it is an excellent choice for portable electronics devices such as mobile phones, improves the reliability and strength of BGA, and the pads effectively improve the strength of the SMD pads. Among several disadvantages of the SMD pads are that the fabrication process is much more complicated and requires high precision which increases the manufacturing costs.

\section{Epoxy-Resin (FR-4)}

The solder joints use epoxy-resin to maintain the strength and improve adhesion of the solder joints contributing to increased and improved insulation. Epoxy-resin is considered to have lower cost material, it is simple with high reliability in the chip or package bonding, and it has been greatly utilised as a competitive bonding material. Epoxy-resin (FR-4) is highly attractive amongst automotive cars and electronic packages.

\section{Silicon (Si) Die}

A die is a semiconducting material on which a circuit is fabricated. The silicon die is a fully functional chip and contains circuitry to perform a specific function which is essential for manufacturing semiconductors found in many electronic devices.

\section{Methodology}

We use finite element (FE) simulation in this work which comprises ANSYS simulation details, finite element modelling and analysis. The material properties for the lead-based eutectic Sn63Pb37, and lead-free $\mathrm{SnAgCu}$ (SAC): SAC305, SAC387, SAC396 and SAC405 solder alloy materials are sourced from several works. The flow chart of the simulation methodology is presented in Fig. 1. For this research, ANSYS workbench R19.0 was employed to simulate and solve the FE model and includes:
1. CAD Connectivity
2. Geometry Pre-Processing
3. Meshing
4. Materials Support 


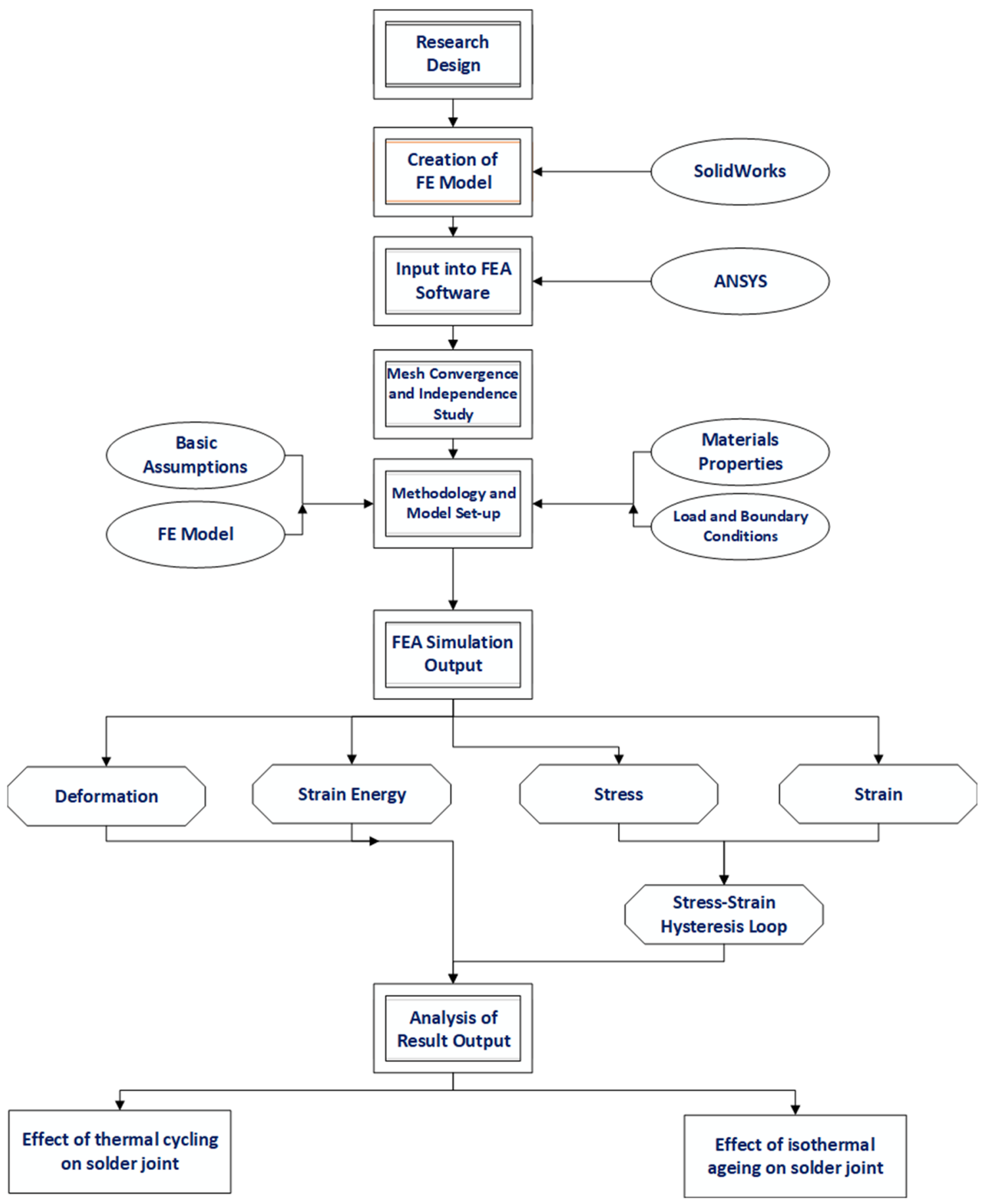

Fig. 1. A schematic of the modelling processes.

5. Boundary Condition Setup

6. Analysis Types (Static structural)

7. Post Processing

8. Solution

\section{Simulation Process}

The finite element analysis (FEA) simulation was carried out using ANSYS R19.0 software. Several procedures are involved in the FEA simulation investigated in this research. The simulation processes for the creep failure are summarised in the chart presented in Fig. 1. The FEA simulation procedure starts with the research design, creation of FE model using SolidWorks, inputting the FE model file into ANSYS R19.0 software, model set-up (mesh convergence and independence study, mesh generation and geometry, material properties input, and application of load and boundary conditions). 


\section{Finite Element (FE) Methods}

A three-dimensional (3D) FE model of a BGA package soldered on PCB is created using SolidWorks software. The full FE model is presented in Fig. 2, along with a quarter of the full model. The details of the package before assembly on the PCB is shown in Fig. 3a, while Fig. 3b presents the detailed structure of a bump before assembly on a PCB. The components of the BGA package include silicon $(\mathrm{Si})$ die, substrate (FR-4), solder ball, epoxy-resin and copper $(\mathrm{Cu})$ pad. The package details and the component dimensions are presented in Tables II and III. The FE model has adequately meshed before inputted into ANSYS R19.0 FEM software where its static structural response to induced thermal loads was simulated. The recommended PCB pads and dimensions are obtained from TopLine Corporation. ${ }^{70}$ The necessity to use a quarter of the full model (Fig. 2) is to reduce simulation solver time whilst achieving significant accurate results. The solder structure in the $\mathrm{FE}$ model with a full X Plane-BGA structure in tetrahedral mesh is presented in Fig. 4.

\section{Materials and their Properties Used in the Assembly}

The materials in the BGA assembly and their mechanical properties are presented in Tables IV. The material properties are obtained from several works published in the literature. The critical component material in the assembly includes solder alloys, copper $(\mathrm{Cu})$ pad, epoxy-resin, (FR-4) board, PCB mask, and silicon ( $\mathrm{Si}$ ) die. The assembly does not contain intermetallic compounds (IMC) because the effect is not the focus of this study. All the materials were modelled as linear elastic and isotropic substances except the PCB and the solder alloys, which are simulated using the orthographic material properties and Garofalo creep relations, respectively. Creep is considered the principal deformation mechanism in solder joints. ${ }^{12,71}$ The chart showing the difference in materials properties used in FEA simulation in ANSYS is presented in the graph (Fig. 5).
The thermo-mechanical behaviour of the silicon (Si) die, epoxy-resin (FR-4) board, copper $(\mathrm{Cu})$ pad and PCB mask were modelled as isotropic, linear elastic and temperature independent. Limiting the simulation time and retain sufficient accuracy, only the solder interconnections were modelled with nonlinear behaviour. The published constitutive properties of lead-free solder alloys are very scarce, and validation of some existing models is still ongoing. For this study, the creep behaviour of lead-based solder alloy is assumed to obey the Garofalo-Arrhenius creep constitutive law. The Garofalo-Arrhenius's creep constitutive constants for solder alloy is presented in Table V.

Thermal cycling tests at various temperatures and strain rates are usually carried out in order to evaluate the deformation behaviour of solder alloy materials. The power creep law combined set of data of stress, $\sigma$, strain rate, $\dot{\varepsilon}$, and temperature, $T$ as shown in Eq. 1. ${ }^{23}$

$$
\dot{\varepsilon}=A \exp \left(-\frac{Q}{R T}\right) \sigma^{n_{p}}
$$

Additionally, the Garofalo sine hyperbolic equation is also employed in describing the creep behaviour of materials in a wider range of temperatures and strain rates. It is used by many electronics packaging mechanics researchers.

Garofalo's hyperbolic sine law $^{23}$ is stated thus and is shown in Eq. 2:

$$
\dot{\varepsilon}=A[\sinh (\alpha \sigma)]^{n} e^{\left(-\frac{Q}{R T}\right)}
$$

where $\dot{\varepsilon}$ is creep strain rate, $A$ is a material constant, $\alpha$ is a multiplier of hyperbolic sine law, which is obtained from curve fitting to experimental data by using linear and nonlinear least-squares regression, $\sigma$ is the applied shear stress, $n$ is the stress exponent which can be determined from creep deformation map, it can be found that the deformation mechanism is dislocation creep, so $n$ is between 5 and 7. $Q$ is the activation energy, $R$ is the universal gas constant, and $T$ is the temperature in Kelvin.

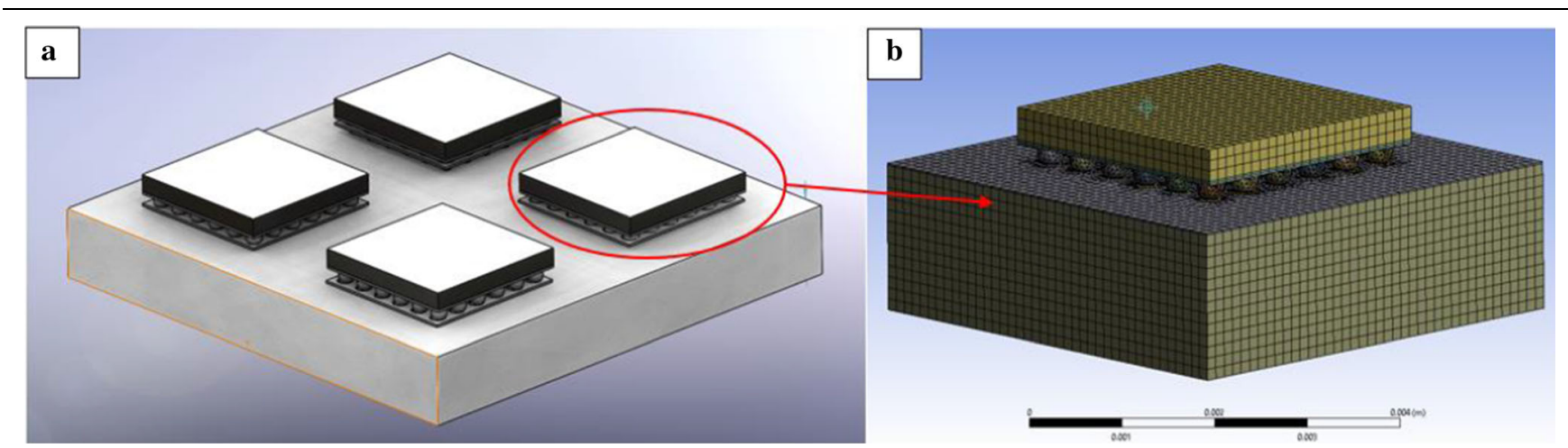

Fig. 2. (a) Full model of assembly (b) A quarter assembly of the model with meshing on a PCB using the solder joints as the interconnection technology (with 226,252 nodes and 59,105 elements) in tetrahedral mesh. 


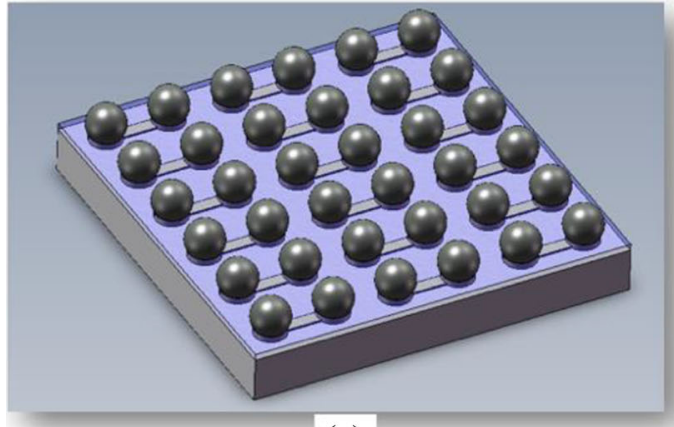

(a)

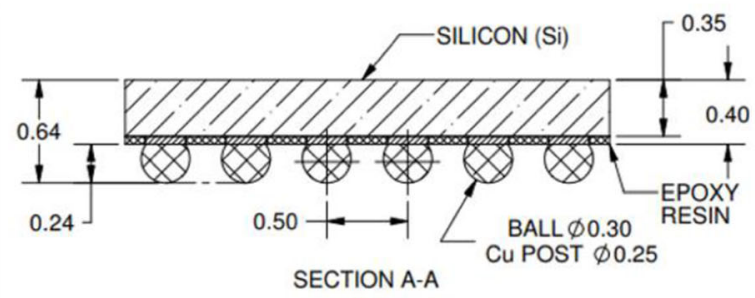

(b)

Fig. 3. Details of the package before assembling on a PCB showing: (a) SolidWorks full model (b) Sectional view (in mm).

Table II. Components and the package and their architecture

\begin{tabular}{|c|c|c|c|c|c|c|c|}
\hline Balls & Ball matrix & Pitch & Size & Substrate & Part number & Reference & Quick view \\
\hline 36 & $6 \times 6$ & $0.5 \mathrm{~mm}$ & $3 \mathrm{~mm}$ & Silicon (Si) & WLP36T.5C-DC067D & TopLine ${ }^{70}$ & 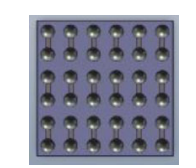 \\
\hline
\end{tabular}

Table III. Package dimensions ${ }^{70}$

\section{Package}

\section{PCB}

Solder mask thickness

Substrate (Silicon)

$\mathrm{Cu}$ pad diameter

$\mathrm{Cu}$ pad thickness

Die (epoxy-resin)

Solder ball height

Number of solder balls

Solder ball pitch diameter

PCB mask

\begin{tabular}{c} 
Dimensions (mm where applicable) \\
\hline $5 \times 5 \times 1.6$ \\
0.05 \\
$3 \times 3 \times 0.35$ \\
0.36 \\
0.02 \\
$5 \times 5 \times 0.05$ \\
0.24 \\
36 \\
0.30 \\
0.05
\end{tabular}

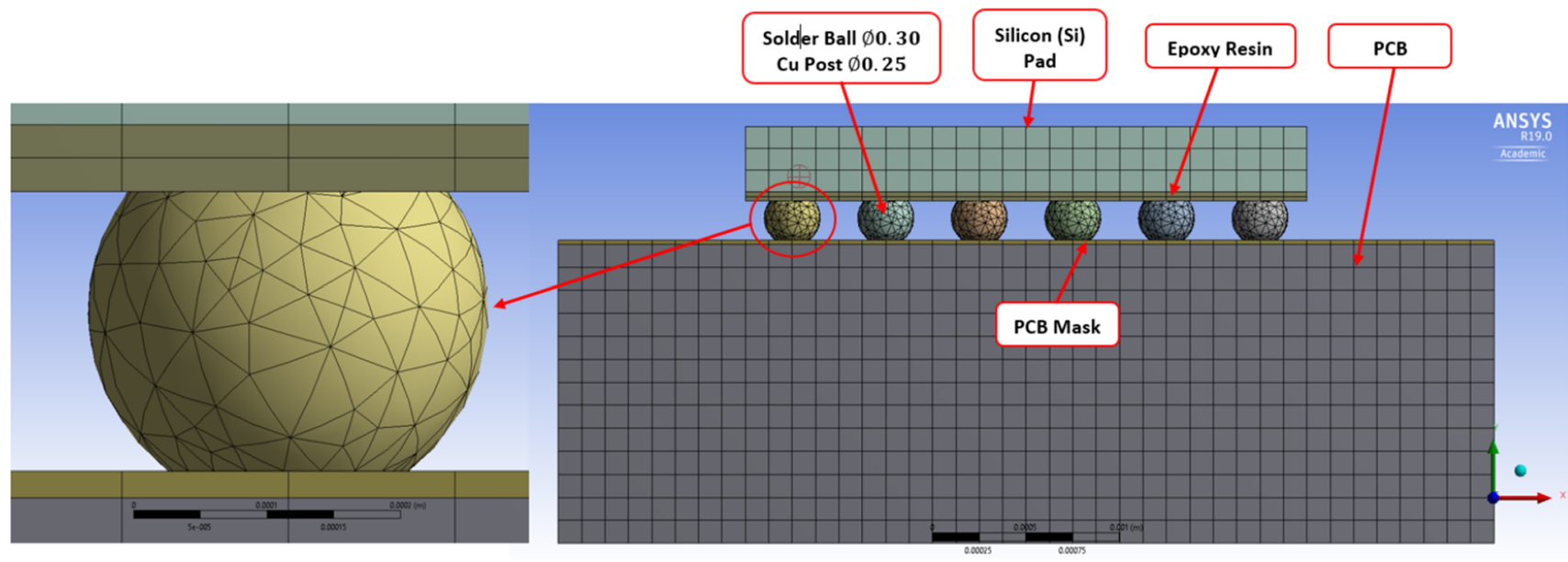

Fig. 4. Solder structure in the FE model with a detailed X Plane-BGA structure in tetrahedral mesh. 
Table IV. Material properties for the BGA on PCB components

\begin{tabular}{|c|c|c|c|c|c|c|c|c|c|c|c|}
\hline \multirow[b]{2}{*}{$\mathbf{S} / \mathbf{n}$} & \multirow[b]{2}{*}{ Material } & \multirow[b]{2}{*}{ Reference } & \multicolumn{3}{|c|}{ Young's modulus (GPa) } & \multicolumn{3}{|c|}{ CTE $\left(\mathbf{p p m} /{ }^{\circ} \mathbf{C}\right)$} & \multicolumn{3}{|c|}{ Poisson's ratio } \\
\hline & & & $\boldsymbol{E}_{\boldsymbol{x}}$ & $\boldsymbol{E}_{\boldsymbol{y}}$ & $\boldsymbol{E}_{\boldsymbol{z}}$ & $\alpha_{x}$ & $\alpha_{y}$ & $\alpha_{z}$ & $v_{x y}$ & $v_{x z}$ & $v_{y z}$ \\
\hline 1 & Silicon (Si) Die & TopLine ${ }^{70}$ & 110 & & & 2.60 & & & 0.24 & & \\
\hline 2 & PCB Mask & Zahn $^{72}$ & 4.14 & & & 30.0 & & & 0.40 & & \\
\hline 3 & $\mathrm{Cu} \mathrm{Pad}$ & Nguyen et al. ${ }^{73}$ & 129 & & & 17.0 & & & 0.34 & & \\
\hline 4 & PCB & Amalu and Ekere 21 & 27 & 27.0 & 22.0 & 14.0 & 14.0 & 15.0 & 0.17 & 0.20 & 0.17 \\
\hline 5 & Epoxy Resin & TopLine ${ }^{70}$ & 29.9 & 25.1 & 70.0 & 12.0 & 15.0 & & 0.16 & 0.14 & \\
\hline 6 & Sn63Pb37 & Long et al. ${ }^{74}$ & 56 & & & 20.0 & & & 0.30 & & \\
\hline 7 & SAC305 & TopLine ${ }^{70}$ & 51 & & & 23.5 & & & 0.40 & & \\
\hline 8 & SAC387 & Beyer et al. ${ }^{75}$ & 45 & & & 17.6 & & & 0.36 & & \\
\hline 9 & SAC405 & Eckermann et al. ${ }^{76}$ & 44.6 & & & 20.0 & & & 0.42 & & \\
\hline 10 & SAC396 & Stoyanov et al. ${ }^{77}$ & 43 & & & 23.2 & & & 0.30 & & \\
\hline
\end{tabular}

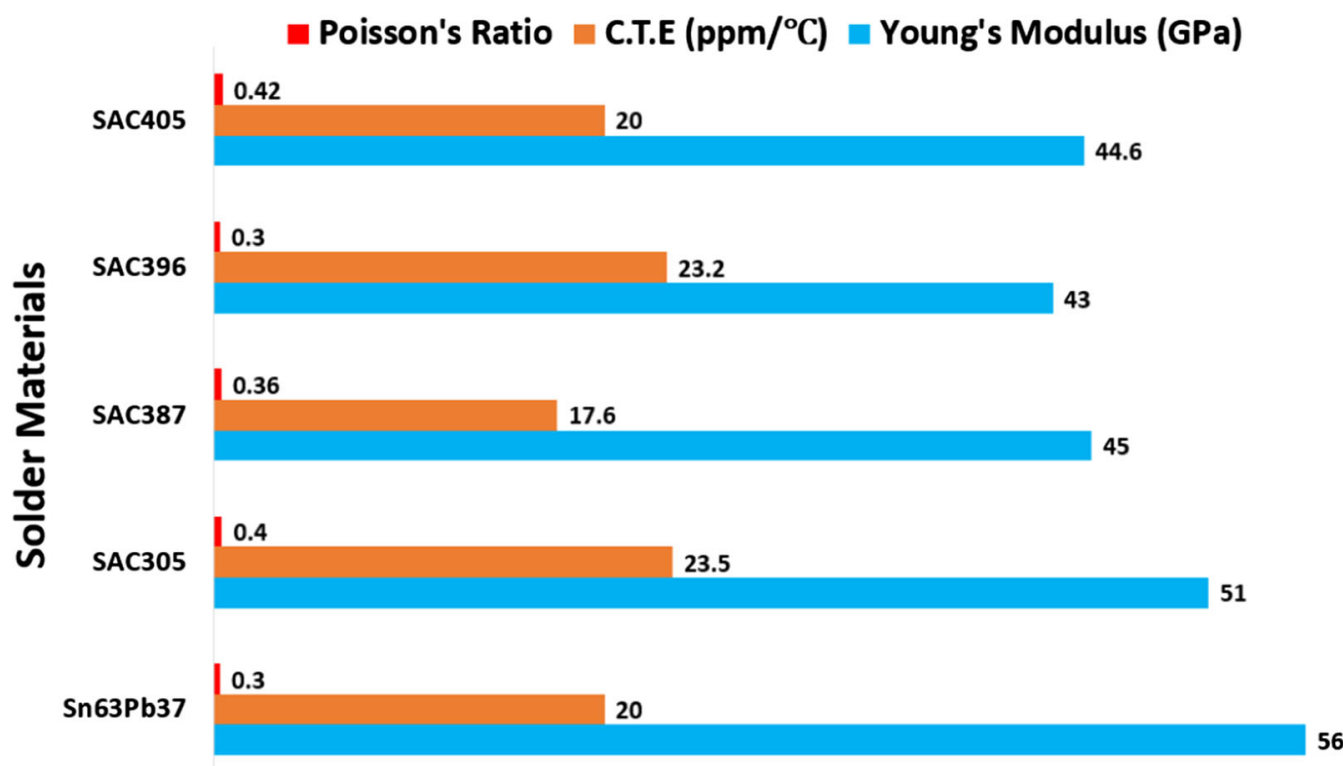

Fig. 5. Plot showing the comparison of the materials properties used for the FEA simulation showing Young's modulus $(\mathrm{GPa}), \mathrm{CTE}\left(\mathrm{ppp} /{ }^{\circ} \mathrm{C}\right)$ and Poisson's Ratio.

Table V. Garofalo-Arrhenius's Creep Constitutive Constants for Solder Alloy

\begin{tabular}{|c|c|c|c|c|c|c|}
\hline Constitutive model & Solder alloy & Reference & $\boldsymbol{A}\left(s^{-1}\right)$ & $\alpha\left(\mathbf{M P a}^{-\mathbf{1}}\right)$ & $n$ & $\boldsymbol{Q}(\mathbf{K J} / \mathbf{m o l})$ \\
\hline \multirow[t]{5}{*}{ Garofalo sine-hyperbolic } & Sn63Pb37 & Wiese, et al. ${ }^{78}$ & $1.0 \times 10$ & 0.1000 & 2.0 & 44.90 \\
\hline & SAC305 & Vianco $^{79}$ & $2.63 \times 10^{3}$ & 0.0453 & 5.0 & 52.40 \\
\hline & SAC387 & Schubert et al. ${ }^{78}$ & $3.20 \times 10^{4}$ & 0.0370 & 5.1 & 65.30 \\
\hline & SAC405 & Wang et al. ${ }^{80}$ & $1.7 \times 10$ & 0.14 & 4.2 & 55.00 \\
\hline & SAC396 & Lau et al. ${ }^{29}$ & $4.41 \times 10^{5}$ & 0.0050 & 4.2 & 45.00 \\
\hline
\end{tabular}

Pan $^{81}$ proposed modifying Garofalo's hyperbolic since law with a grain size effect for the eutectic $\mathrm{Pb} /$ Sn alloy as well as the original terms in Eq. 3:

$$
\dot{\varepsilon}=A[\sinh (\alpha \sigma)]^{n}(d)^{-p} e^{\left(-\frac{Q}{R T}\right)}
$$

where $d$ is the grain size and $p$ is the grain size exponent.
Even though Eq. 3 performs very well representing test data, the grain size effect was omitted due to the difficulty of acquiring the material properties parameters for the grain size and grain size exponent for SAC305, SAC387, SAC396 and SAC405. Available data for eutectic solder alloy were reported by Shi et al. ${ }^{82}$ whose test data do not provide the effect of grain size on creep behaviour 
because the experiment was done for a single grain size, $d=30 \mu \mathrm{m}$ why the work Kashyap and Murty, ${ }^{83}$ grain size information of $d=$ 9.7 and $28.4 \mu \mathrm{m}$ were applied. Results by the authors show that grain size is essential in constitutive creep model and that the stress exponent factor, $n$, is also dependent on the grain size. The benefit of the Garofalo equation relies on its ability to predict the creep behaviour of materials subjected to a vast range of temperatures and strain rates. It is understood that grain size plays an essential role in the creep model, especially the one proposed by $\mathrm{Pan}^{81}$ to include grain size and grain size exponent. The difficulty of acquiring material parameters for the SAC solder makes the evaluation difficult using these models. Furthermore, the hyperbolic sine model provides a better representation of the entire stress regime. Experiments will have to be conducted, which is outside the scope of this research and will form part of the future work designed for this investigation.

\section{Loading and Boundary Conditions}

Two specific loading conditions used in this investigation are isothermal ageing and thermal cycling. The influence of thermal ageing on the performance of solder joints cannot be underestimated. This study investigates thermal ageing for short and long-term effects on solder joints in harsh environments. The solder joints are aged at $-40^{\circ} \mathrm{C}, 25^{\circ} \mathrm{C}, 75^{\circ} \mathrm{C}$ and $125^{\circ} \mathrm{C}$ for 45 days $(64,800 \mathrm{~min})$ in an ANSYS simulation environment. The research conducted by Sabbah et al. ${ }^{80}$ examined the high-temperature ageing of microelectronics assemblies with SAC solder joints. The BGA soldered on PCB was simulated using the properties of the material presented in Tables III and IV. The ageing parameters are relevant for harsh application environments present under the hood of cars, aerospace, and defence applications. There have been several studies, including one by $\mathrm{Ma}$ et al., ${ }^{84}$ that have established how the creep resistance of SAC solders decreases with an increase in time and temperature during isothermal ageing. $\mathrm{Ma}^{85}$ similarly investigated the influence of elevated temperature ageing on the reliability of lead-free solder joints. The researchers mentioned that the lead-free SAC alloys and lead-based eutectic samples were aged at various intervals from 0 to 6 months at several elevated temperatures $\left(80^{\circ} \mathrm{C}, 100^{\circ} \mathrm{C}, 125^{\circ} \mathrm{C}\right.$ and $150^{\circ} \mathrm{C}$ ). An analogous creep test was performed with the lead-based eutectic solder sample (Sn63Pb37) for evaluation and validation of results purposes. The thermal cycling test parameters used in the ANSYS FEA simulation is presented in Table VI.

For the thermal cycling tests, the FE models were subjected to six complete ATCs in 36 steps presented in the thermal cycling plot presented in Fig. 6. The temperature loading started from $22^{\circ} \mathrm{C}$,

\section{Table VI. Thermal cycling test parameters}

\begin{tabular}{lr}
\hline Low temperature $\left({ }^{\circ} \mathrm{C}\right)$ & -40 \\
High temperature $\left({ }^{\circ} \mathrm{C}\right)$ & 150 \\
Ramp rate $\left({ }^{\circ} \mathrm{C} / \mathrm{min}\right)$ & 15 \\
Dwell time $(\mathrm{min})$ & 5 \\
Cycle period $(\mathrm{min})$ & 42 \\
\hline
\end{tabular}

dwelled at $-40^{\circ} \mathrm{C}$, at a rate of $15^{\circ} \mathrm{C} / \mathrm{min}$ and ramped up to $22^{\circ} \mathrm{C}$, for $1380 \mathrm{~s}$ and had an excursion temperature $(\mathrm{ET})$ of $150^{\circ} \mathrm{C}$, for $1908 \mathrm{~s}$ where it dwelled for $600 \mathrm{~s}$. This is based on IEC 60749-25 temperature cycling and JEDEC Standard JESD22A104D. ${ }^{81,82}$ The ambient temperature used in the simulation environment is $22^{\circ}$ Cand is the starting temperature in the thermal cycle loading. The composition of lead-free SAC alloys (SAC305, SAC387, SAC396 and SAC405) and the lead-based eutectic Sn63Pb37 solder are presented in Table VII. The assemblies were supported such that the conditions of the structure at the supports are:

At the PCB base, $y=0$, and $u_{(y)}=0$;

Top surface $u_{(y)}=0, u_{(x)}$ and $u_{(z)}$ are free.

$u_{(x)}, u_{(y)}$ and $u_{(z)}$ represent the displacement in the $x, y$ and $z$ directions , respectively. The bottom surface of the PCB was fixed in the $Y$ direction and displaced in the $X$ and $Z$ directions. Table $\mathrm{V}$ shows the thermal cycling test parameters used for the FE simulations.

For this study, we have considered creep test temperature of $-40^{\circ} \mathrm{C}, 25^{\circ} \mathrm{C}, 75^{\circ} \mathrm{C}$ and $125^{\circ} \mathrm{C}$ for 45 days $(64,800 \mathrm{~min})$ for the thermal ageing test. Moreover, the estimated value of the activation energy indicates that mass transport controlled through grain boundary diffusion is crucial for lead-rich coarsening under ageing treatment. For these studies, the BGA on the PCB model was simulated using the properties of the material presented in Tables IV and V for the lead-free $\mathrm{SnAgCu}$ and lead-based eutectic solder alloys for 45 days $(64,800 \mathrm{~min})$.

\section{Basic Assumptions}

The basic assumptions employed in the FEA research methodology are as follows:

- All the materials were modelled as linear elastic and isotropic materials except the solder and PCB which are simulated using the Garofalo creep relations and orthographic materials, respectively.

- All materials including the solder joint were assumed homogeneous at load steps.

- The assemblies were assumed to be in a stressfree state at a room temperature of $22^{\circ} \mathrm{C}$ which was also the starting temperature of the thermal cycle loading. 


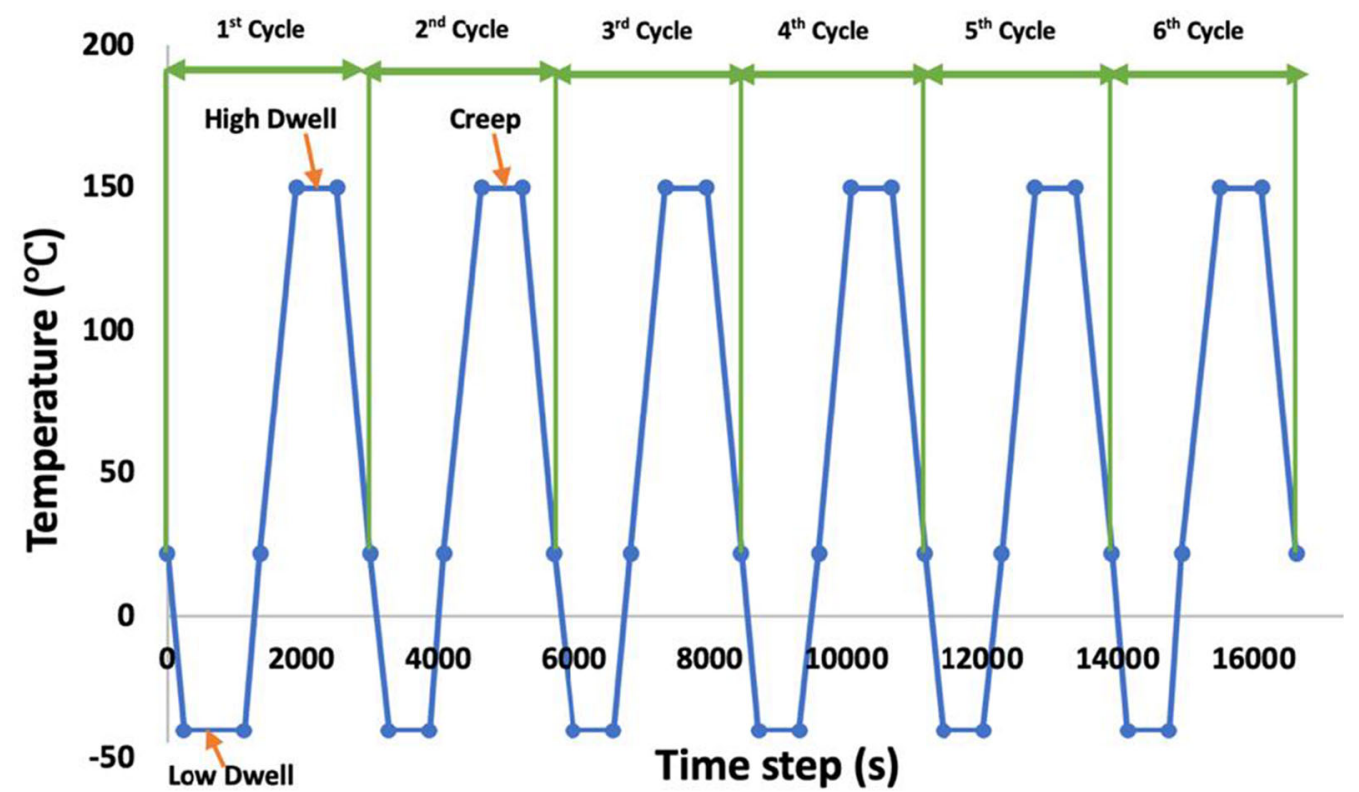

Fig. 6. Thermal cycling boundary conditions used in the FEA simulation.

Table VII. Composition of lead-free eutectic and lead-based SAC solders test samples

\begin{tabular}{|c|c|c|c|c|}
\hline Sample & SnAgCu alloys & Composition & Typical melting temperature $\left({ }^{\circ} \mathbf{C}\right)$ & Recommended by \\
\hline 1 & SAC305 & $\mathrm{Sn}-3.0 \mathrm{Ag}-0.5 \mathrm{Cu}$ & $\begin{array}{l}\text { Solidus: } 217^{\circ} \mathrm{C} \\
\text { Liquidus: } 220^{\circ} \mathrm{C}\end{array}$ & JEITA (Japan) \\
\hline 2 & SAC387 & $\mathrm{Sn}-3.8 \mathrm{Ag}-0.7 \mathrm{Cu}$ & $\begin{array}{l}\text { Solidus: } 217^{\circ} \mathrm{C} \\
\text { Liquidus: } 219^{\circ} \mathrm{C}\end{array}$ & European Union (EU) \\
\hline 3 & SAC405 & $\mathrm{Sn}-4.0 \mathrm{Ag}-0.5 \mathrm{Cu}$ & $\begin{array}{l}\text { Solidus: } 217^{\circ} \mathrm{C} \\
\text { Liquidus: } 222^{\circ} \mathrm{C}\end{array}$ & Global \\
\hline 4 & SAC396 & $\mathrm{Sn}-3.9 \mathrm{Ag}-0.6 \mathrm{Cu}$ & $\begin{array}{l}\text { Solidus: } 217^{\circ} \mathrm{C} \\
\text { Liquidus: } 221^{\circ} \mathrm{C}\end{array}$ & iNEMI (USA) \\
\hline 5 & Lead-based eutectic & $\mathrm{Sn} 63 \mathrm{~Pb} 37$ & $\begin{array}{l}\text { Solidus: } 183^{\circ} \mathrm{C} \\
\text { Liquidus: } 183^{\circ} \mathrm{C}\end{array}$ & Eutectic Solder (Standard) \\
\hline
\end{tabular}

- The initial stress in the assemblies which may be accumulated from the reflow soldering process is neglected, and all contact surfaces are assumed to be bonded with perfect adhesion.

- The material property of the solder bump is nonlinear and temperature dependent. In other words, other solders are linear and temperature independent.

- Process variations were not considered, and IMC growth was ignored.

- Every interface of the materials is assumed to be in contact with each other.

\section{RESULTS AND DISCUSSION}

The results of this investigation are presented under four key headings. These are: Effect of isothermal ageing on creep response of different solders, effect of thermal cycling on creep response of different solders, stress-strain hysteresis loop of the solders and, reliability of BGA solder joint interconnections.

\section{Effect of Isothermal Ageing on Creep Response of Different Solders}

Electronic devices containing BGAs soldered on PCB operate in constant, elevated temperature conditions. The constant, elevated temperature operation induced degradation in the BGA joints. The joint degradation is determined by modelling the BGA assembly with isothermal loading and the solder with suitable creep model. The prediction is imperative, considering that solder creep deformation is significant at device operating homologous temperature circa $\sim 0.5$ and above. For isothermal ageing, the temperatures considered are $-40^{\circ} \mathrm{C}, 25^{\circ} \mathrm{C}, 75^{\circ} \mathrm{C}$ and $150^{\circ} \mathrm{C}$ while the corresponding homologous temperatures for the solders are: $0.50,0.65,0.76$ and 0.93 for lead-based eutectic Sn63Pb37; 0.46, 0.60, 0.71 and 0.86 for SAC305; $0.47,0.61,0.71$ and 0.86 for SAC405; 0.46, 0.61, 
0.71 , and 0.86 for SAC387 and $0.46,0.60,0.70$ and 0.86 for SAC396.

The effect of isothermal ageing on the creep response of the different solders is investigated in four different contexts. These are discussed in the following section.

\section{Effect of Isothermal Ageing on Magnitude of Total Strain on the Solders}

The test vehicles are simulated for the effect of isothermal ageing on the joint's degradation. The output function of the simulation is the total strain on the solders. The results obtained are presented in Figs. 7 and 8. The plot of equivalent total strain, $\varepsilon$ against temperature $T$ is shown in Fig. 7. A positive linear correlation describes the relationship between the two quantities. For SAC387, the relation is explicitly stated thus: $\varepsilon=9 \times 10^{-5} T-0.0018$ while for SAC405 it is expressed as, $\varepsilon=3 \times 10^{-5} T-0.0008$. These relations can be used to predict the strain of untried temperatures.

It could be observed in Fig. 7 that SAC405 accumulated the lowest magnitude of strain, whereas SAC387 accumulated the highest strain magnitude. At $25^{\circ} \mathrm{C}$ ambient temperature, all solders have zero strain magnitude, at temperatures lower and higher than this critical point, they demonstrate negative and positive strain values, respectively. Knowledge of the strain response of the solders is used to predict their stress response at various temperatures. Figure 8 shows the schematic distribution of strain in the solder joints. The regions of maximum damage are seen at the top of the joints. This is a critical site for failure and thus is the location for strengthening.

\section{Effect of Isothermal Ageing on Magnitude of Strain Energy Density of the Solders}

The strain energy density $E_{d}$ dissipated by the solder joints during isothermal ageing is investigated via the FEA simulation for 45 days $(64,800 \mathrm{~min})$. The plot is presented in Fig. 9. It is observed that a parabola fits the plotted points. The parabola for lead-free SAC387 is expressed as $E_{d}=$ $0.0003 T^{2}+0.0483 T-1.2915$ while the expression for lead-based eutectic $\mathrm{Sn63Pb37}$ solder is $E_{d}=9 \times 10^{-5} T^{2}+0.0064 T-0.4012$. The plot presented in Fig. 9 shows that the lead-based eutectic $\mathrm{Sn} 63 \mathrm{~Pb} 37$ solder has the lowest $E_{d}$ followed closely by lead-free SAC405 solder. SAC387 accumulated the highest $E_{d}$ density and thus is more susceptible to failures than the other solders examined. Extrapolating the plot and using the mathematical expressions generated, the $E_{d}$ of the solders at various temperatures can be predicted. The schematic obtained in the simulation results show the regions of solder joint with critical strain energy magnitude. The top of the solder joints was observed to experience the highest strain energy.

\section{Effect of Isothermal Ageing on Magnitude of Equivalent (von Mises) Stress in the Solders}

The equivalent (von Mises) stress accumulated in the solder joints is investigated. The results are presented in Fig. 10. It can be seen in the plot that as temperature increases, the stress magnitude increases. The relationship between stress and temperature for SAC305 is given by $\sigma=3.152 T-68.167$. This solder recorded the highest stress magnitude. Similarly, the relationship for SAC405 is expressed as $\sigma=1.543 T-34.983$. The

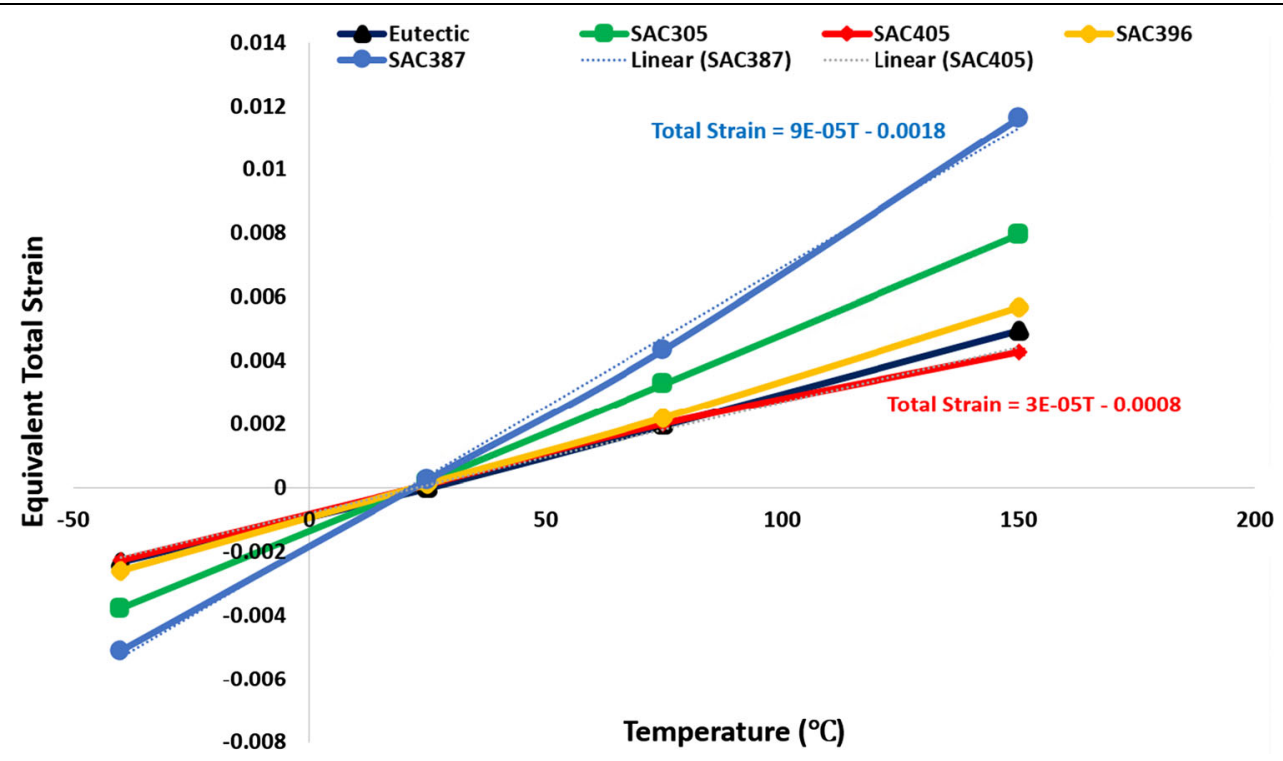

Fig. 7. Plot of strain rate versus temperature for eutectic lead-based Sn63Pb37 and lead-free SAC solders subjected thermal ageing. 

Array (BGA) Soldered on Printed Circuit Board (PCB)

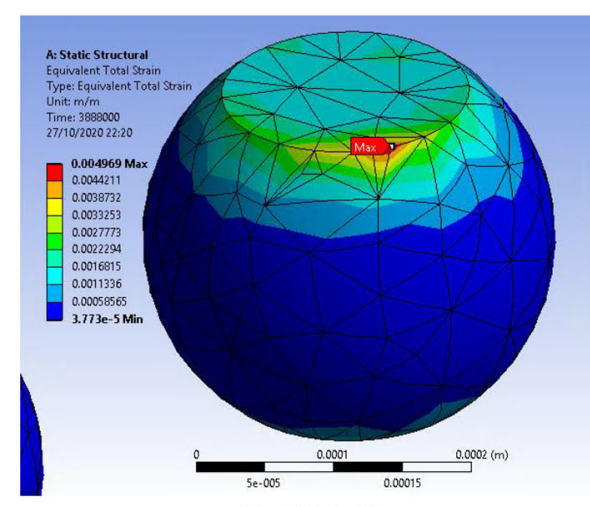

Sn63Pb37

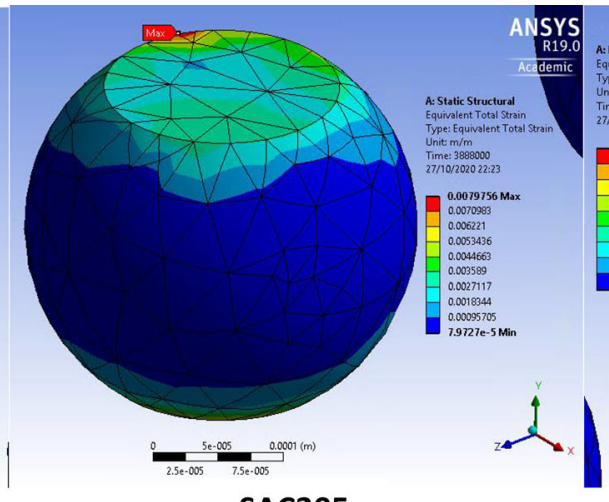

SAC305

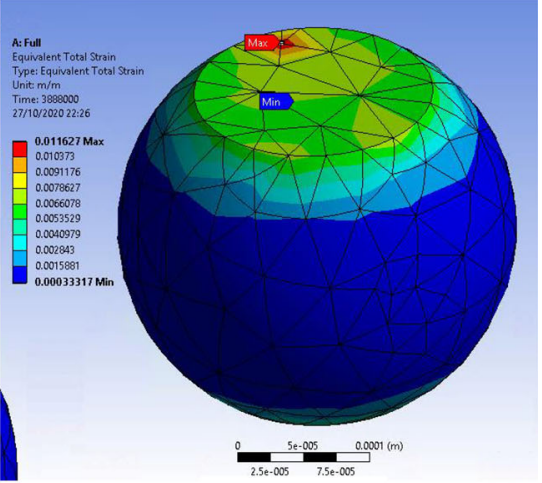

SAC387

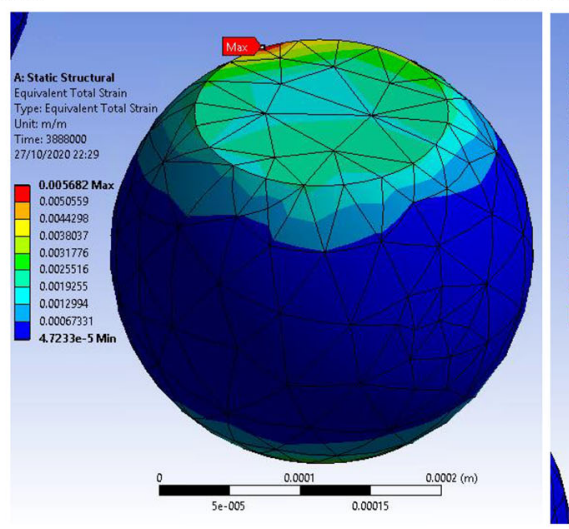

SAC396

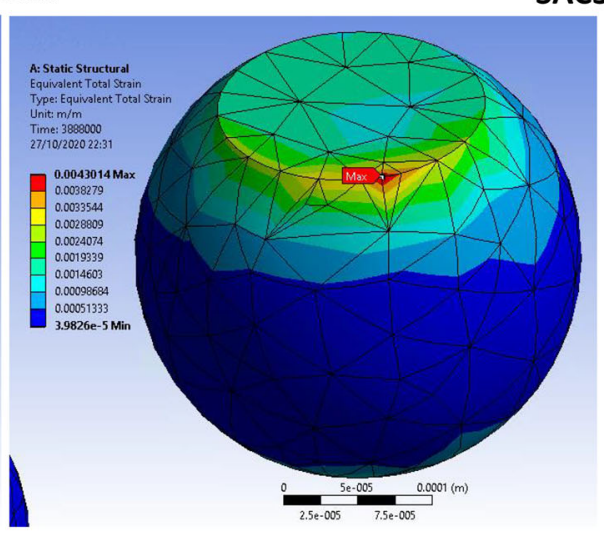

SAC405

Fig. 8. Schematic distribution of total strain for SAC396, SAC405, SAC387, SAC305 and Sn63Pb37 solders joints subjected to $150^{\circ} \mathrm{C}$ isothermal ageing.

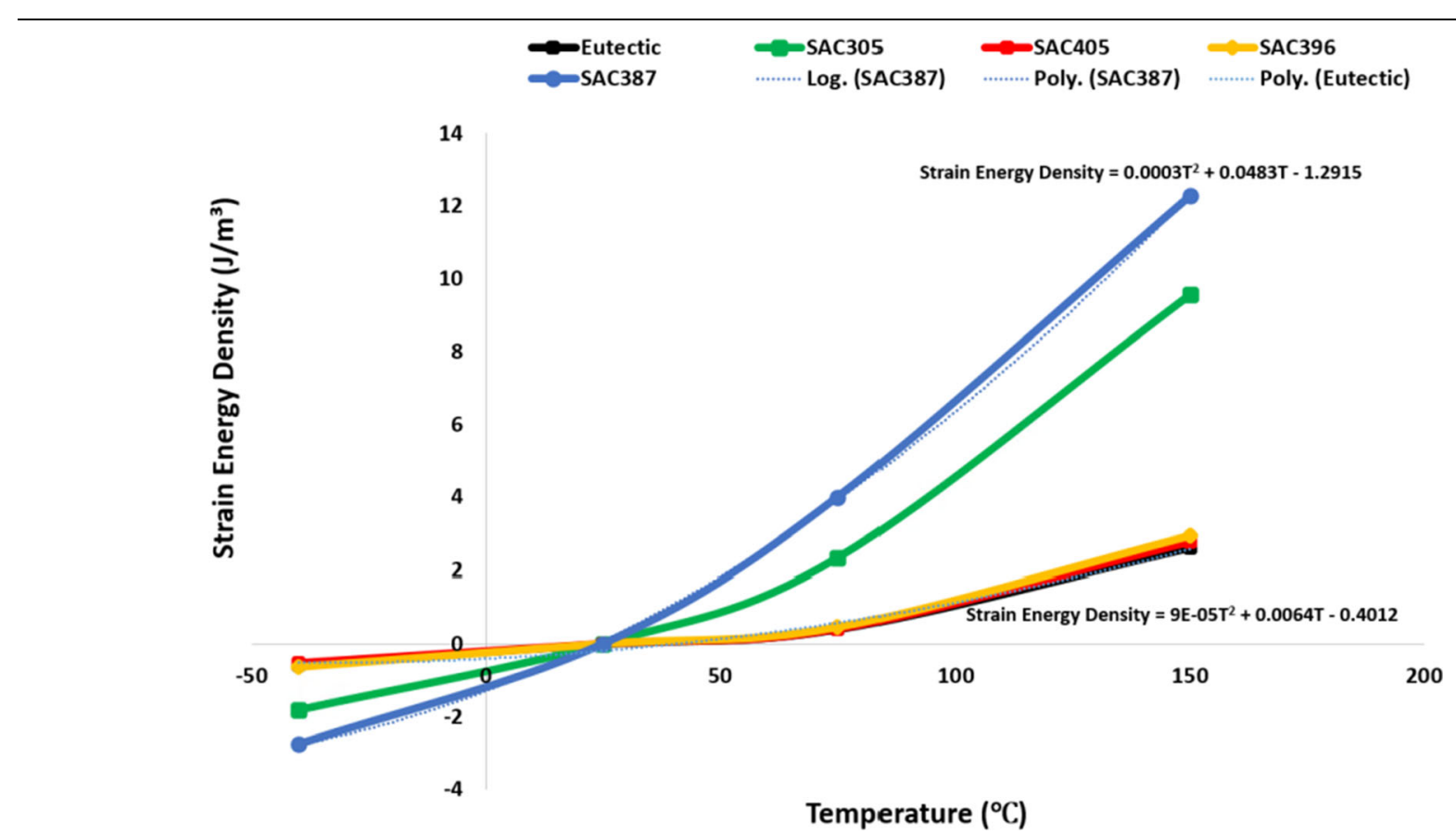

Fig. 9. Plot of strain energy density $E_{d}$ versus temperature $T$ for lead-based eutectic Sn63Pb37 and lead-free SAC solders subjected to thermal ageing. 


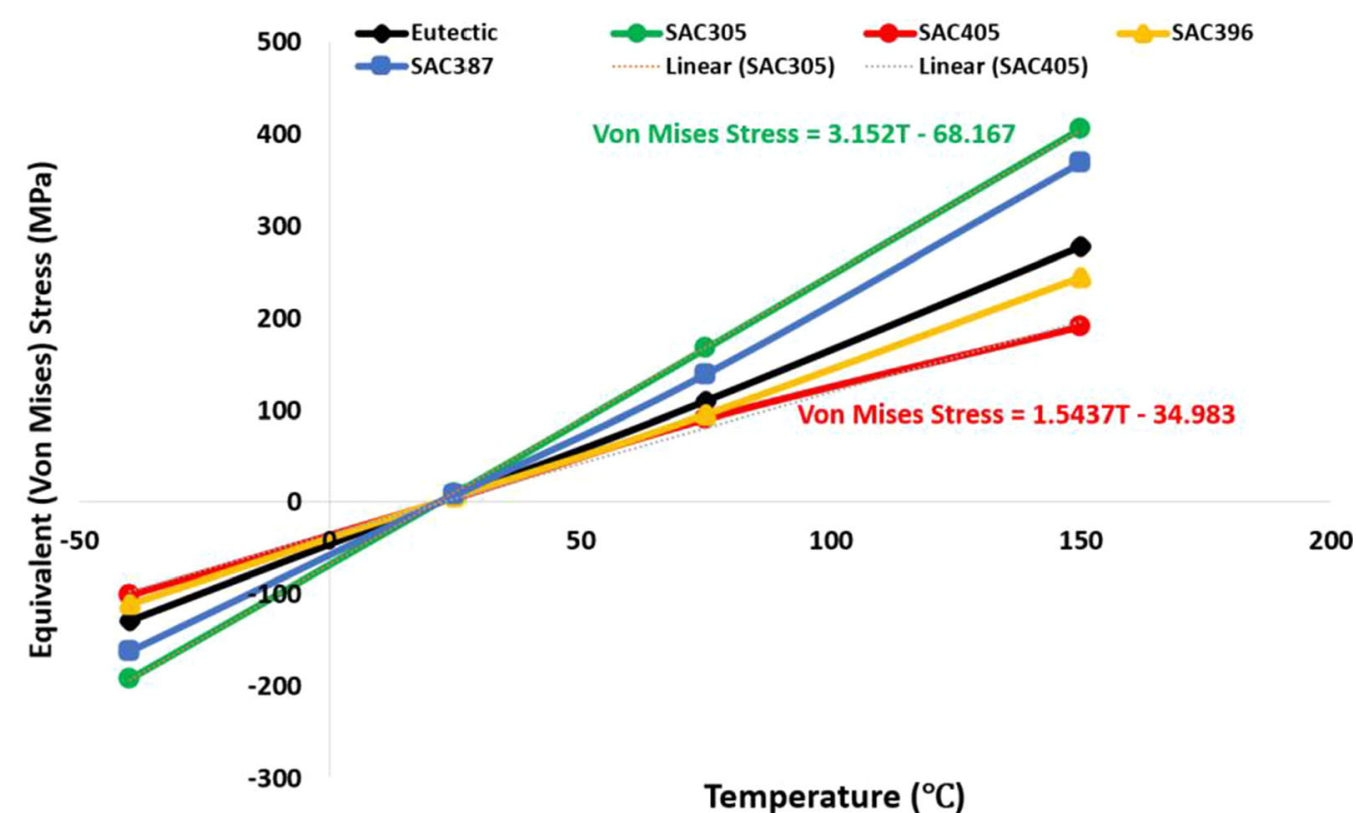

Fig. 10. von Mises stress plot versus temperature for lead-based eutectic Sn63Pb37 and lead-free SAC solders subjected isothermal ageing.

solder recorded the least stress magnitude. The schematic representation of the stress distribution shows that the top and bottom of the solder bumps accumulate the most serious damage. These are the site of crack initiation and propagation.

\section{Effect of Thermal Cycling on Creep Response of Different Solders}

Similar to the discussion on isothermal loading, the analysis of the effect of thermal cycling on solder creep response is investigated and presented in three contexts. These are discussed in the following sections.

\section{Effect of Thermal Cycling on Magnitude} of Equivalent (von Mises) Stress in the Solders

Cyclic thermal stress in electronic packages is known as a fundamental challenge to electronics reliability. The reliability is associated with crack initiation and propagation, which culminates in systems failure if not controlled. The simulation output results are used to plot the graph presented in Fig. 11.

Figure 11 presents a generic profile for all the solders. At the beginning of the cycle, solder joints are not stressed. At about $2000 \mathrm{~s}$ of cycle time, the solders accumulated a significant amount of stress. Further cycling up to $16,000 \mathrm{~s}$ produces about $6 \%$ increase in lead-free SAC305, SAC396 and leadbased eutectic $\mathrm{Sn} 63 \mathrm{~Pb} 37$. The stress accumulated in SAC405 is relatively unchanged over the cycle time while the stress accumulated in SAC387 decreases. The schematic stress distribution in the solder bump shows that the stress is critical at the edges of the solder bump. Thus, it is a desirable area for crack nucleation. Generally, SAC305 accumulated the highest stress magnitude while SAC405 accumulated the lowest stress magnitude. Therefore, SAC405 is the most stable and thus less likely to attain its yield stress first.

\section{Effect of Thermal Cycling on the Magnitude of Strain Rate of the Solders}

The strain rate outputs of the simulation are presented in Fig. 12. Similar to the stress, the strain rate ramped up substantially at $2000 \mathrm{~s}$ of cycle time. For the next $14,000 \mathrm{~s}$ the strain rate increased about 5.0\% for lead-free SAC305, SAC396 and leadbased eutectic Sn63Pb37. There are observed decreases in the change in strain rate for lead-free SAC405 and SAC387. These characterise the behaviour of the solder joints under thermal cycling and over the time range. It can be seen that SAC387 and SAC405 accumulated the highest and least strain rate in the solder joints. The schematic obtained for the FEA simulation output shows areas with high strain rate concentration in red. This suggests that SAC405 is the most stable solder joint during the thermal cycle loading, while SAC387 is the least stable joint.

\section{Effect of Thermal Cycling on Magnitude of Strain Energy Density of the Solders}

The FEA simulation results obtained for strain energy density of the solder joint alloys are presented in Fig. 13. The figures show profiles as described for stress and strain in the previous sections. The magnitude of the creep strain energy accumulated in various solder joints varies. It can be seen that SAC387 has the highest strain energy 
Effective Solder for Improved Thermo-Mechanical Reliability of Solder Joints in a Ball Grid Array (BGA) Soldered on Printed Circuit Board (PCB)

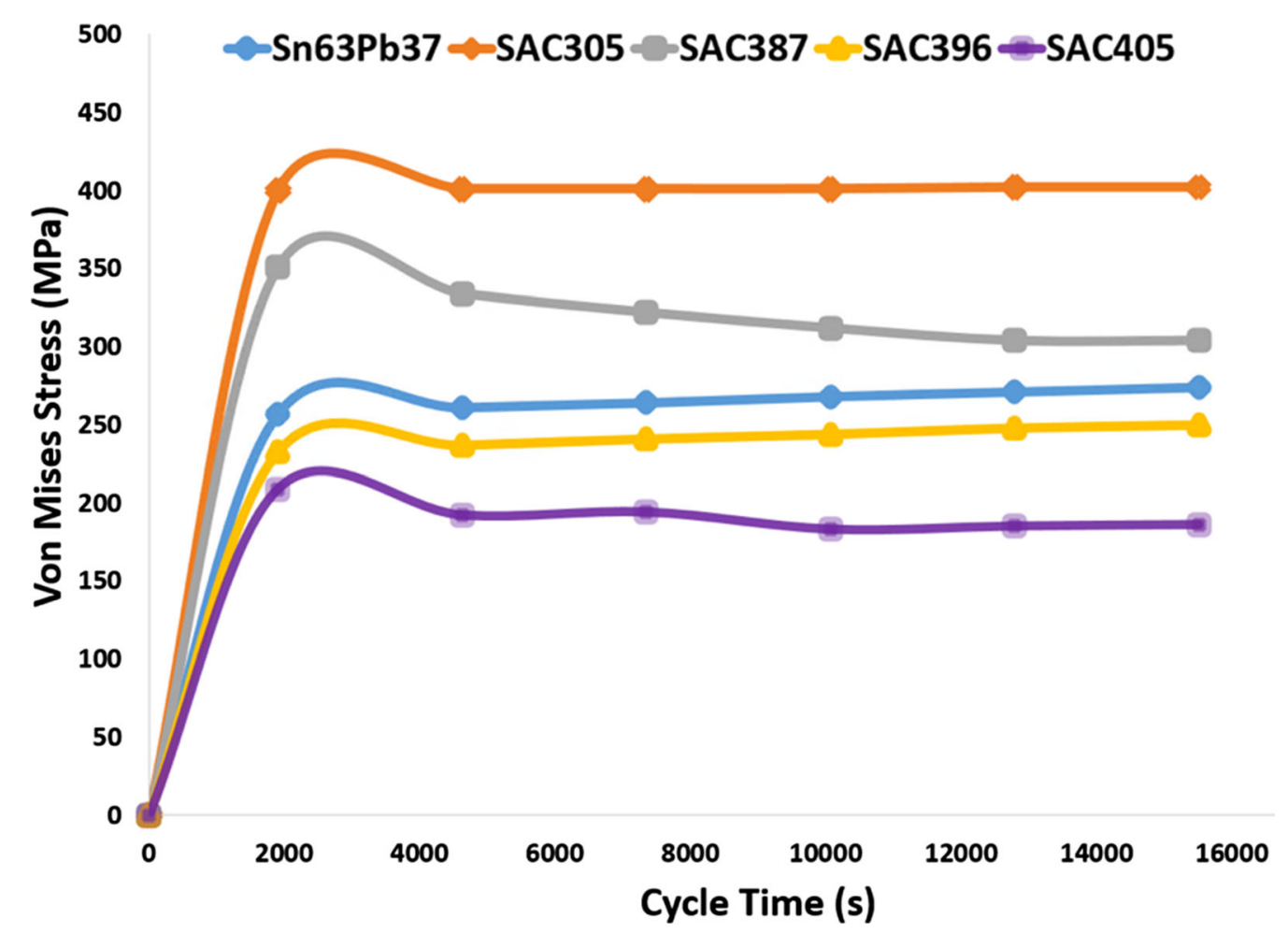

Fig. 11. Plot of von Mises stress for lead-based eutectic Sn63Pb37 and SAC solders subjected to thermal cycling.

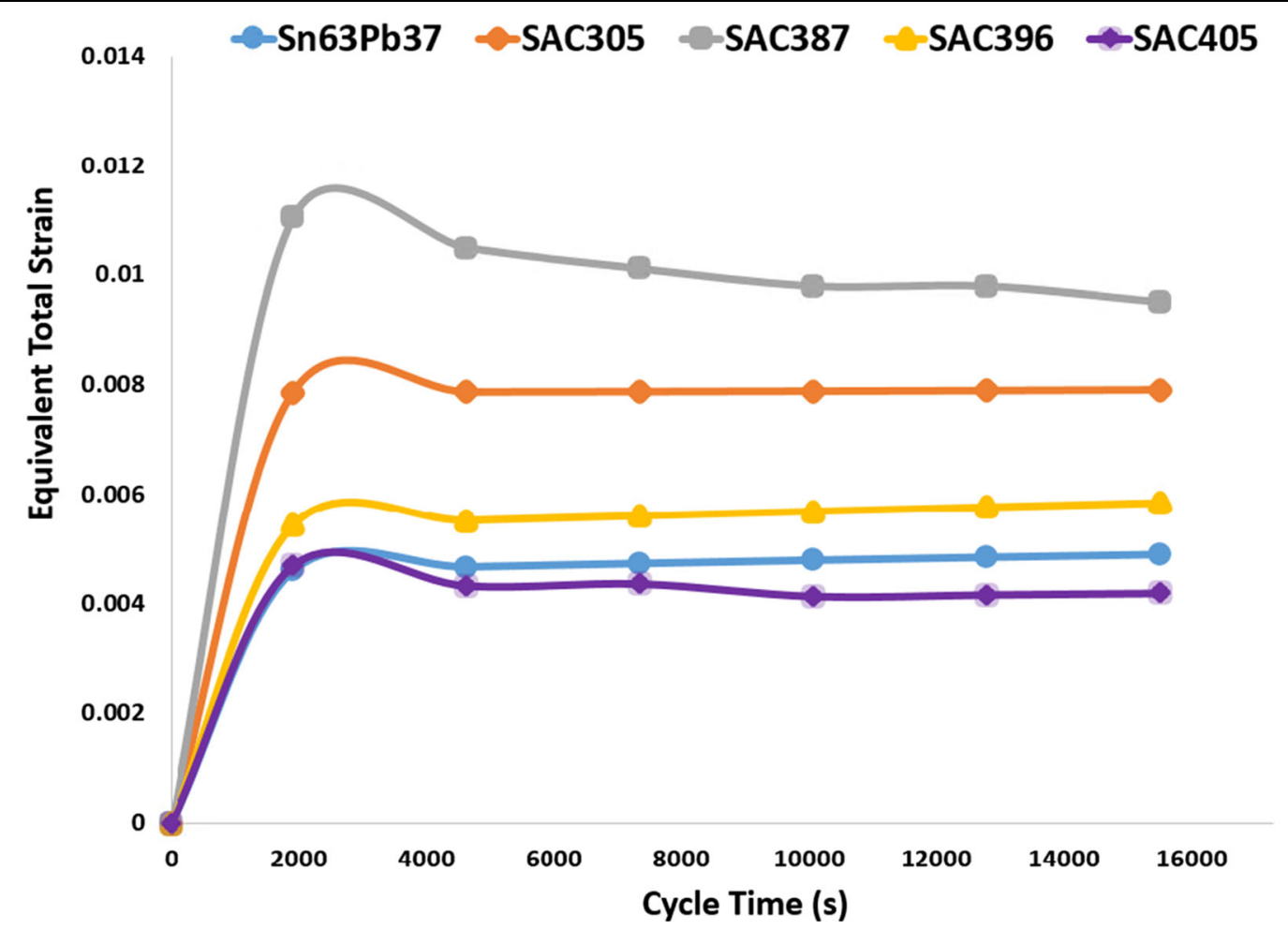

Fig. 12. Plot of equivalent total strain for lead-based eutectic Sn63Pb37 and SnAgCu solders subjected to thermal cycling. 


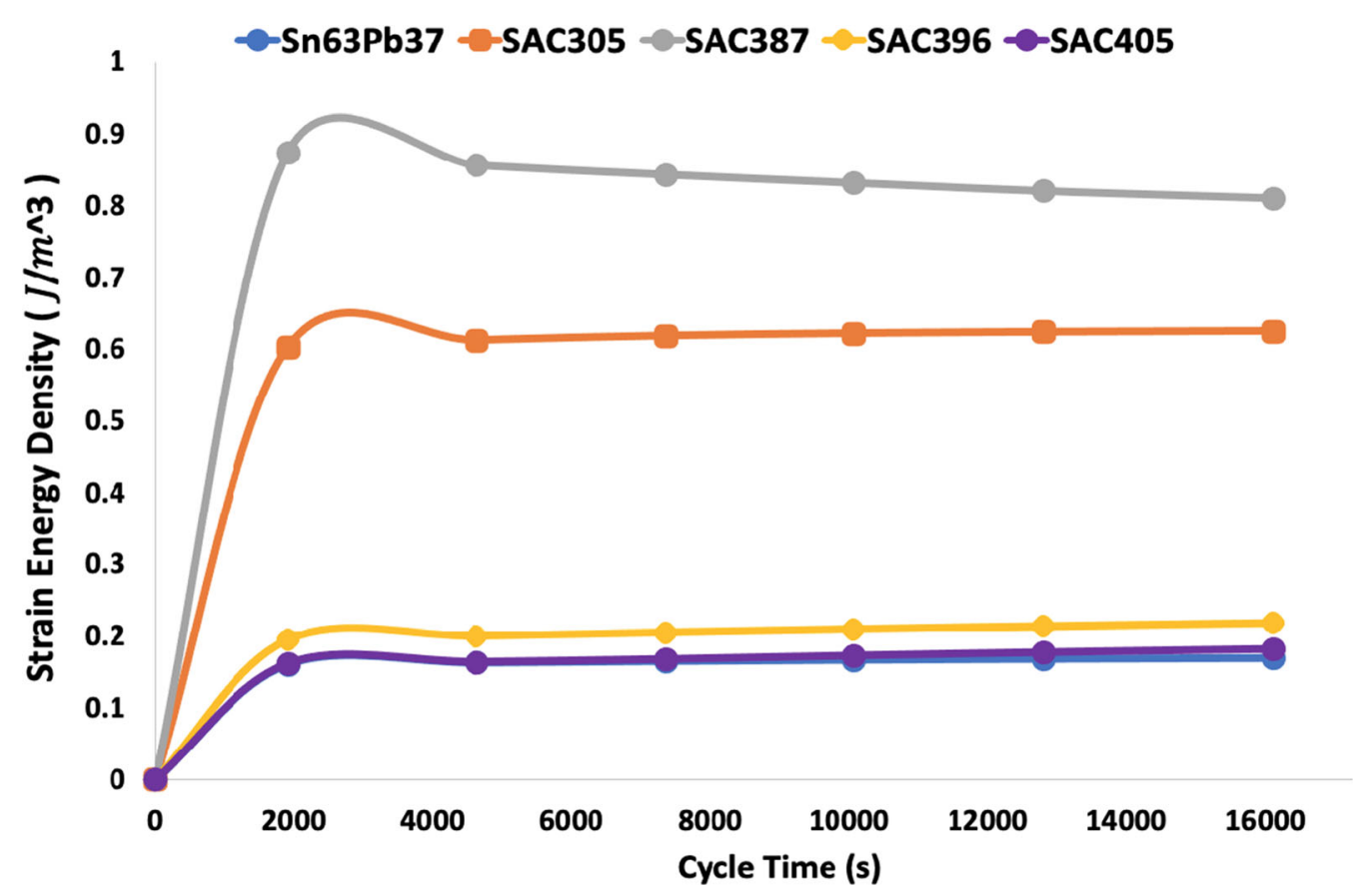

Fig. 13. Strain energy density plots for lead-based eutectic Sn63Pb37 and SnAgCu solders subjected to thermal cycling.

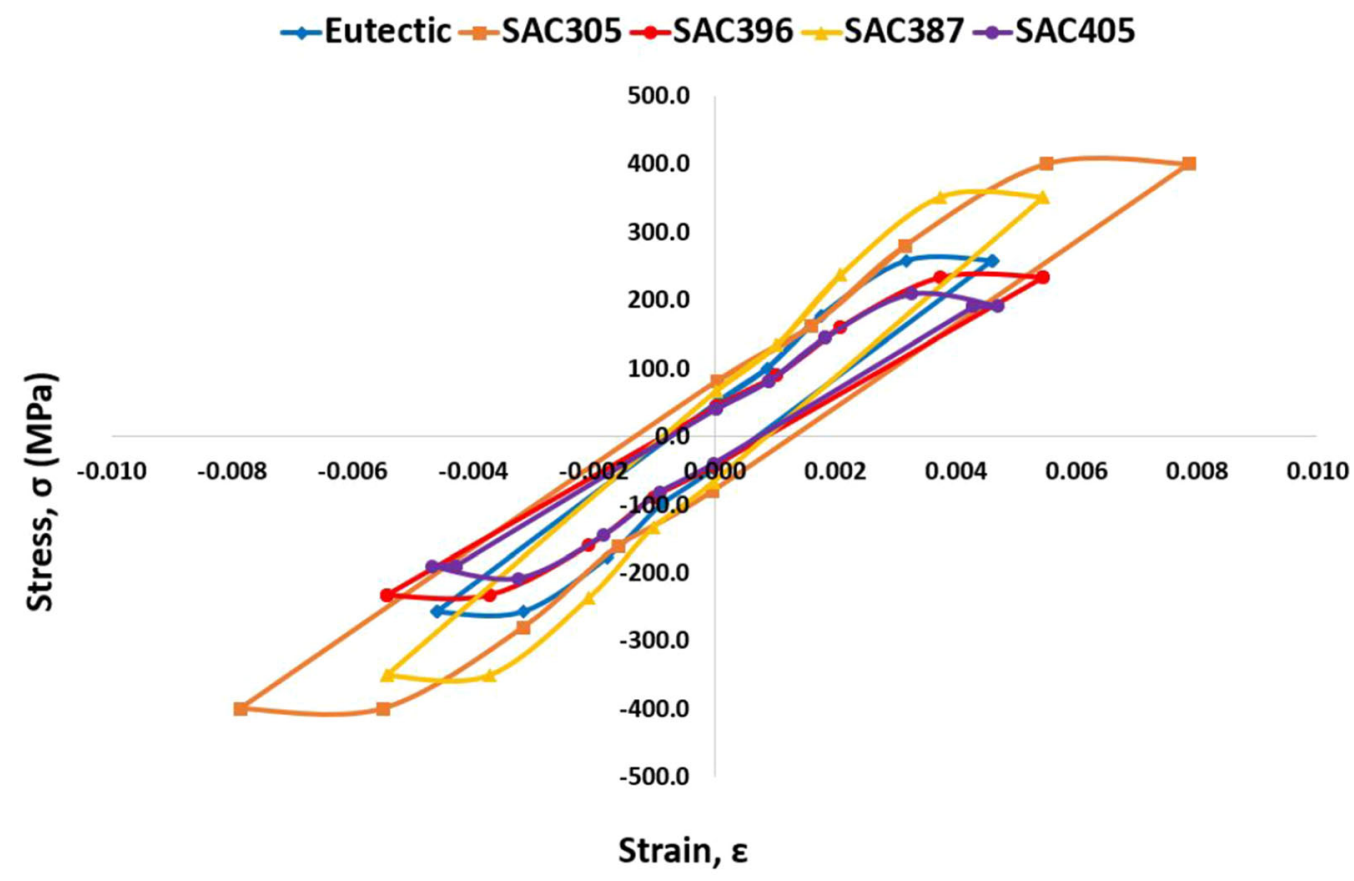

Fig. 14. Representation of schematic of solder joint hysteresis loops for lead-based eutectic Sn63Pb37 and lead-free SAC305, SAC396, SAC387 and SAC405 solders.

density while SAC405 and lead-based eutectic Sn63Pb37 have the lowest strain energy density for lead-free and lead-based solders, respectively. The schematic shows damage distribution areas and strain energy density for the solders. The critical portion of the solder bump is shown in red.

\section{Stress-Strain Hysteresis Loop of the Solder} Joints of Various Solders

Another method of determining the magnitude of damage in solder joints is to measure the area under the stress-strain plot. The plot is known as the hysteresis loop. The hysteresis loop plot of the solder 


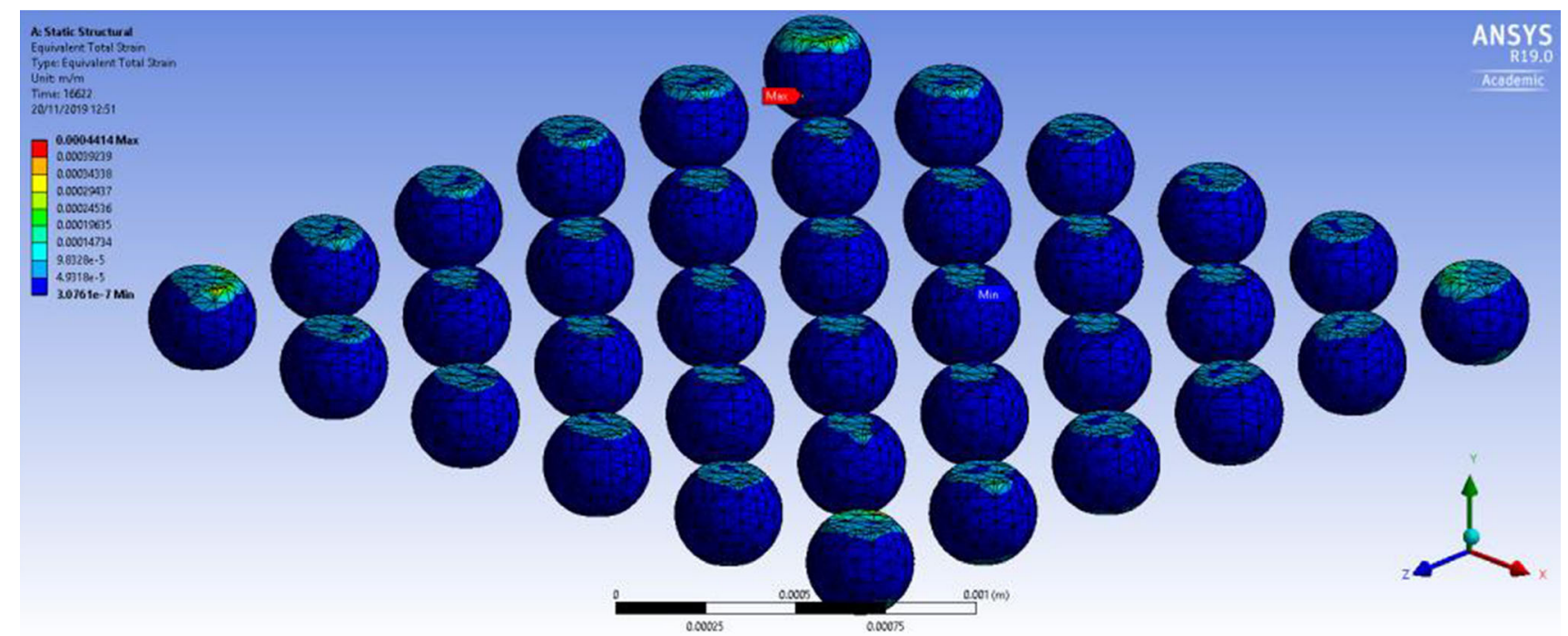

Fig. 15. Schematic distribution of damage on the solder bump of the BGA soldered on PCB after simulation modelling.

joints considered in the study is presented in Fig. 14. The figure shows the hysteresis loop for eutectic lead-based $\mathrm{Sn} 63 \mathrm{~Pb} 37$ and lead-free SAC305, SAC396, SAC387 and SAC405 solder alloys. The concept of the loop is that the larger the area, the more serious the accumulated damage in the solder joint. The upper portion of the hysteresis loop represents the loading portion (tensile), while the lower portion represents the unloading portion (compression) of the cycle. From the hysteresis loop plot presented in Fig. 14, it can be seen that SAC405 has the lowest dissipated energy per cycle, followed by lead-based eutectic Sn63Pb37. The SAC305 accumulated the highest damage followed by SAC387 and then SAC396.

\section{Reliability of BGA Solder Joints Interconnections}

A general damage distribution of the solder bumps of the BGA soldered on PCB is shown in Fig. 15. It can be observed that the damage concentrates at the top flange of the corner solder joints. These are the solder regions that should be strengthened for increased solder joint reliability. The observation correlates significantly well with the results obtained by Libot et al. ${ }^{86,87}$ who investigated the experimental strain energy density dissipated in SAC305 solder joints during different thermal cycling conditions using strain gauges measurements. This shows that the damage occurs at the top and bottom of the results as seen from the simulation. Similarly, results obtained by Pierce et al. $^{88}$ show similar outcomes with high strain regions in the critical solder ball determined with FEM analysis and observation of the thermo- mechanical fatigue crack localised in the solder bulk on the component side.

The different damage behaviour of the solder substrate in thermal cycling test can be explained using the material properties of the solder. The temperature fluctuation on the substrate edges is a key damage driver during a thermal cycling test-it results in larger shear forces on the substrate edges. ${ }^{89}$ A plot of the results of the thermal cycling and isothermal ageing is presented in Fig. 16. The chart shows the reliability position of each solder against the other solders for the different temperature loading conditions. The plot shows that SAC405 achieved the smallest numbers in the ranking while the SAC387 achieved the highest numbers. The lower the number in the ranking, the smaller the damage in the solder. Consequently, on average, it can be inferred that SAC405 solder demonstrated the least damage in the investigated loading conditions. Similar results were obtained for the thermal cycling test. Several other investigational (experiments) results by An et al., ${ }^{90} \mathrm{Hsieh}$ and Tzeng ${ }^{91}$ George et al., ${ }^{92}$ and Syed ${ }^{93}$ has corroborated the FEA simulation results obtained from this research.

\section{CONCLUSIONS}

This paper investigated the effects of isothermal ageing and temperature cycling loading on the thermo-mechanical properties of lead-based eutectic Sn63Pb37 and lead-free SAC305, SAC387, SAC396 and SAC305 solder alloys used as ball grid array (BGA) solder joints. Based on the FEA simulation results leading to some findings, it is concluded that 
घon Mises Stress $\quad$ Strain Rate $\quad$ Strain Energy Deformation

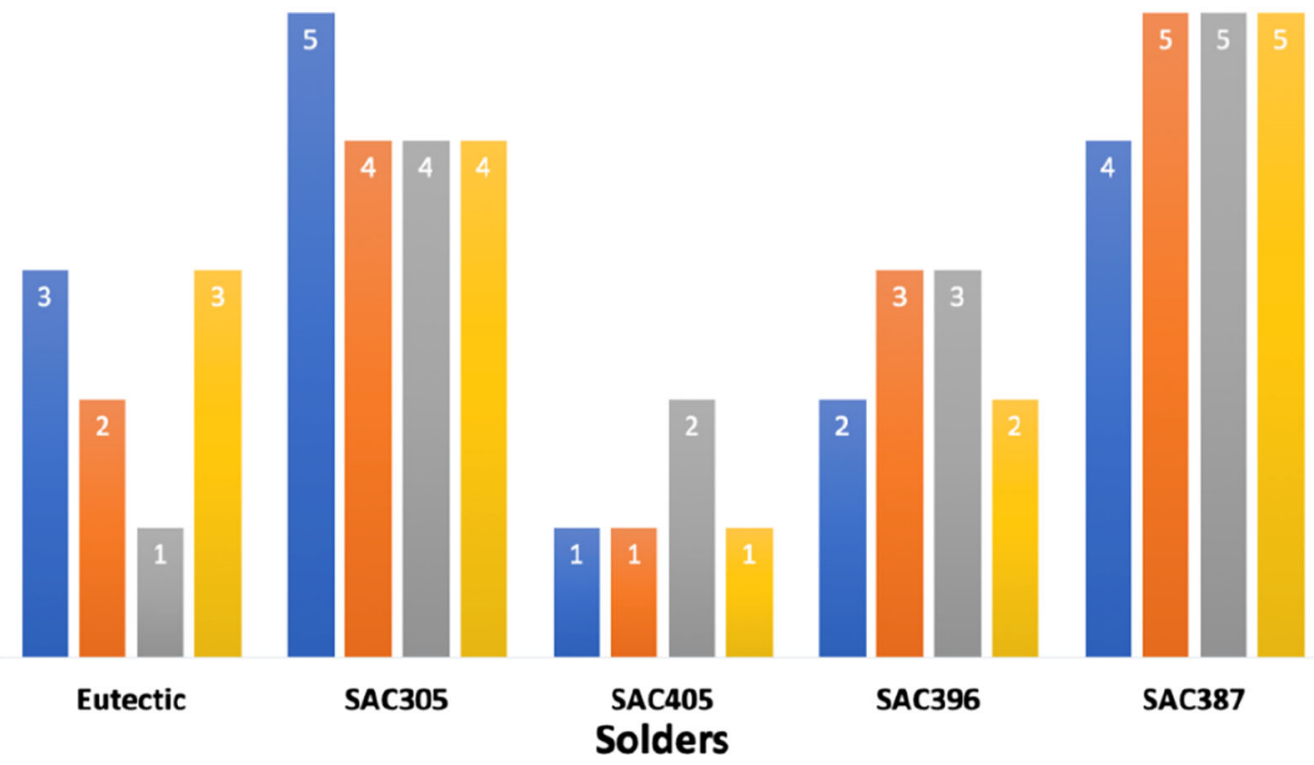

Fig. 16. Plot of thermal cycling and isothermal ageing reliability positions of solders interconnect [Reliability increases from 1 to 5 : $1=$ best and $5=$ worse].

SAC405 and SAC396 are the effective lead-free solders.

Specific conclusions drawn include:

- The lead-free SAC405 solder joint is the most effective solder under thermal cycling.

- This conclusion is drawn based on the finding that the solder possesses the lowest magnitudes of stress, strain rate, deformation rate and strain energy density than any other solder considered for temperature cycle loading in this investigation.

- The lead-free SAC396 solder joint is the most effective solder under isothermal ageing operation. The finding that the solder accumulated the minimum magnitudes of stress, strain rate, deformation rate and strain energy density than any other solder considered in this study informed the conclusion.

- The top and bottom of solder joints at the periphery of a BGA soldered onto a printed circuit board (PCB) are the critical sites and position of maximum damage. Strengthening of these joints is therefore recommended. This conclusion is reached based on the observation that the magnitude of damage is highest in the solder joints at the locations in the BGA for all the solder types considered.

- Based on the thermo-mechanical response of both lead-free SAC405 and SAC396 in this study, they are recommended as a suitable replacement for lead-based eutectic Sn63Pb37 solder for improved device thermo-mechanical operations.

\section{ACKNOWLEDGMENTS}

The work reported in part in this article is funded by the School of Mechanical Engineering \& the Built Environment, College of Engineering \& Technology, University of Derby, UK.

\section{CONFLICT OF INTEREST}

The authors declare that they have no conflict of interest.

\section{OPEN ACCESS}

This article is licensed under a Creative Commons Attribution 4.0 International License, which permits use, sharing, adaptation, distribution and reproduction in any medium or format, as long as you give appropriate credit to the original author(s) and the source, provide a link to the Creative Commons licence, and indicate if changes were made. The images or other third party material in this article are included in the article's Creative Commons licence, unless indicated otherwise in a credit line to the material. If material is not included in the article's Creative Commons licence and your intended use is not permitted by statutory regulation or exceeds the permitted use, you will need to obtain permission directly from the copyright holder. To view a copy of this licence, visit http://creativecom mons.org/licenses/by/4.0/.

\section{REFERENCES}

1. K. Kanlayasiri and K. Sukpimai, J. Alloys Compd. (2016). h ttps://doi.org/10.1016/j.jallcom.2016.01.231. 
2. L. Zhang and K.N. Tu, Mater. Sci. Eng R: Rep. (2014). h ttps://doi.org/10.1016/j.mser.2014.06.001.

3. R.J. Coyle, K. Sweatman, and B. Arfaei, JOM 67, 2394 (2015). https://doi.org/10.1007/s11837-015-1595-1.

4. W.J. Plumbridge, Monatshefte fur Chemie (2005). https://doi. org/10.1007/s00706-005-0377-9.

5. F. Ji, S. Xue, L. Zhang, L. Gao, Z. Sheng, and W. Dai, Chin. J. Mech. Eng. English Ed. (2011). https://doi.org/10.3901/c jme.2011.03.428.

6. L. Sun, L. Zhang, S. Juan Zhong, J. Ma, and L. Bao, J. Mater. Sci.: Mater. Electron. 26, 9164 (2015). https://doi.org/ 10.1007/s10854-015-3606-y.

7. Y. Zhang, Z. Cai, J.C. Suhling, P. Lall, and M.J. Bozack, Proceedings - ECTC 2008, vol. C, No. June, p. 99. https://doi. org/10.1109/ectc.2008.4549956.

8. J. Zhang, Z. Hai, S. Thirugnanasambandam, J.L. Evans, M.J. Bozack, R. Sesek, Y. Zhang, and J.C. Suhling, SMTA J. 25 (3), 19 (2012).

9. J.S.S. Hwang and R.M.M. Vargas, Solder Surf. Mt. Technol. 2, 38 (1990). https://doi.org/10.1108/eb037718.

10. C. Basaran, H. Ye, D.C. Hopkins, D. Frear, and J.K. Lin, J. Electron. Packag. Trans. ASME (2005). https://doi.org/10.1 $115 / 1.1898338$.

11. J. Gomez and C. Basaran, Mech. Mater. 38, 585 (2006). h ttps://doi.org/10.1016/j.mechmat.2005.11.008.

12. D. Barbini and M. Meilunas, in IPC APEX EXPO Conference and Exhibition 2013, APEX EXPO 2013, 2013.

13. V. Ramachandran, K.C. Wu, and K.N. Chiang, J. Mech. (2018). https://doi.org/10.1017/jmech.2018.20.

14. V. Ramachandran and K.N. Chiang, IEEE Trans. Device Mater. Reliab. (2017). https://doi.org/10.1109/TDMR.2017.2 751085 .

15. J.H.L. Pang, B.S. Xiong, C.C. Neo, X.R. Zhang, and T.H Low, in Proc. - Electron. Components Technol. Conf., p. 673, 2003. https://doi.org/10.1109/ectc.2003.1216355.

16. G. Chen, X. Zhao, and H. Wu, Adv. Mech. Eng. 9, 1 (2017). h ttps://doi.org/10.1177/1687814017714976.

17. S. Akbari, A. Lövberg, P.E. Tegehall, K. Brinkfeldt, and D. Andersson, Microelectron. Reliab. (2019). https://doi.org/10. 1016/j.microrel.2019.01.006.

18. Y. Zhang, Z. Cai, J.C. Suhling, P. Lall, and M.J. Bozack, Proc. Electron. Compon. Conf. (2009). https://doi.org/10.110 9/ECTC.2009.5074043.

19. B.Z. Hong and L.G. Burrell, IEEE Trans. Compon. Packag. Manuf. Technol. Part A (1995). https://doi.org/10.1109/95.4 65156.

20. K.C. Wu, S.Y. Lin, T.Y. Hung, and K.N. Chiang, IEEE Trans. Device Mater. Reliab. (2015). https://doi.org/10.1109/ TDMR.2015.2462726.

21. E.H. Amalu, N.N. Ekere, C.F. Oduoza, and M.T. Zarmai, NSTI: Advanced Materials - TechConnect Briefs 2015, 2015.

22. E.H. Amalu and N.N. Ekere, J. Manuf. Syst. (2016). http s://doi.org/10.1016/j.jmsy.2016.01.002.

23. F. Garofalo and D.B. Butrymowicz, Phys. Today (1966). h ttps://doi.org/10.1063/1.3048224.

24. Y. Lee and C. Basaran, J. Electron. Packag. Trans. ASME (2011). https://doi.org/10.1115/1.4005288.

25. R. Ebrahimi, S.H. Zahiri, and A. Najafizadeh, J. Mater. Process. Technol. (2006). https://doi.org/10.1016/j.jmatpro tec.2005.06.072

26. M. Zhou and M.P. Clode, Mech. Mater. (1998). https://doi. org/10.1016/S0167-6636(97)00035-5.

27. J. Malaplate, F. Mompiou, J.L. Béchade, T. Van Den Berghe, and M. Ratti, J. Nucl. Mater. (2011). https://doi.org/ 10.1016/j.jnucmat.2010.12.059.

28. A. Fahim, S. Ahmed, M.R. Chowdhury, J.C. Suhling, and P. Lall, in Proceedings of the 15th InterSociety Conference on Thermal and Thermomechanical Phenomena in Electronic Systems, ITherm 2016, vol. C, No. November 2017, p. 1218 , 2016. https://doi.org/10.1109/itherm.2016.7517686.

29. J. Lau, W. Dauksher, and P. Vianco, Proc. Electron. Com pon. Conf. (2003). https://doi.org/10.1109/ectc.2003.1216281.
30. M.T. Zarmai, N.N. Ekere, C.F. Oduoza, and E.H. Amalu, Robot. Comput. Integr. Manuf. 47, 37 (2017). https://doi.org/ 10.1016/j.rcim.2016.12.008.

31. J.H.L. Pang, T.H. Low, B.S. Xiong, X. Luhua, and C.C. Neo, Thin Solid Films (2004). https://doi.org/10.1016/j.tsf.2004.0 5.092 .

32. A. Schubert, R. Dudek, E. Auerswald, A. Gollhardt, B. Michel, and H. Reichl, Proc. Electron. Compon. Conf. (2003). h ttps://doi.org/10.1109/ectc.2003.1216343.

33. J. Zhang, Z. Hai, S. Thirugnanasambandam, J.L. Evans, M.J. Bozack, Y. Zhang, and J.C. Suhling, IEEE Trans. Compon. Packag. Manuf. Technol. 3, 1348 (2013). https://d oi.org/10.1109/tcpmt.2013.2251932.

34. L.F. Coffin Jr., Transactions of the American Society of Mechanical Engineers, vol. 76 (New York, 1954), pp. 931950.

35. S.S. Manson, 'National Advisory Committee for Aeronautics. 1953

36. S. Wiese and S. Rzepka, Microelectron. Reliab. (2004). http s://doi.org/10.1016/j.microrel.2004.04.015.

37. D.R. Shirley, H.R. Ghorbani, and J.K. Spelt, Microelectron. Reliab. (2008). https://doi.org/10.1016/j.microrel.2007.08.00 2.

38. A.R. Syed, J. Electron. Packag. Trans. ASME (1995). http s://oi.org/10.1115/1.2792077.

39. B. Wong, D.E. Helling, and R.W. Clark, IEEE Trans. Compon. Hybrids Manuf. Technol. (1988). https://doi.org/10.110 9/33.16655.

40. A. Syed, Proc. Electron. Compon. Conf. (2004). https://doi. org/10.1109/ectc.2004.1319419.

41. M.M. Hasnine, J.C. Suhling, B.C. Prorok, and M.J. Bozack, in 2007 Proceedings of the 57th Electronic Components and Technology Conference, vol. 37, No. 7, p. 49, 2014. https://doi. org/10.1109/ectc.2014.6897315.

42. J. Morrow, Internal Friction, Damping, and Cyclic Plasticity, 2009.

43. F. Ellyin and D. Kujawski, J. Press. Vessel Technol. Trans. ASME (1984). https://doi.org/10.1115/1.3264362.

44. J.H. Lau and Y. Pao, McGraw-Hill Professional Publishing, 1997.

45. R. Darveaux, K. Banerji, A. Mawer, G. Dody, and J. Lau, Ball grid array Technology, Vol. 13 (New York: McGrawHill, 1995), p. 379.

46. W. Engelmaier, Solder. Surf. Mt. Technol. (1996). https://d oi.org/10.1109/iemt.1995.541031.

47. W. Engelmaier, Solder. Surf. Mt. Technol. (1989). https://d oi.org/10.1108/eb037660.

48. W. Engelmaier, Solder. Surf. Mt. Technol. (1992). https://d oi.org/10.1108/eb037775.

49. H. Qi, N.M. Vichare, M.H. Azarian, and M. Pecht, IEEE Trans. Compon. Packag. Technol. (2008). https://doi.org/10. 1109/TCAPT.2008.921647.

50. J. Pan and J. Silk, in 44th International Symposium on Microelectronics 2011, IMAPS 2011, 2011. https://doi.org/10. 4071/isom-2011-wp2-paper2.

51. Z.P. Wang, Y.M. Tan, and K.M. Chua, Microelectron. Reliab. (1999). https://doi.org/10.1016/S0026-2714(99)00057-8.

52. B.N. Muthuraman and B. Canete, 2018 Proceedings of the 7th Electronic System-Integration Technology Conference, ESTC 2018, 2018. https://doi.org/10.1109/estc.2018.854650 4.

53. Z.W. Zhong and T.Y. Tee, Proc. IEEE (2009). https://doi.org/ 10.1109/JPROC.2009.2014657.

54. S.W. Yoon, J.K. Hong, H.J. Kim, and K.Y. Byun, IEEE Trans. Electron. Packag. Manuf. (2005). https://doi.org/10. 1109/TEPM.2005.847398.

55. H. Juso, Y. Yamaji, T. Kimura, K. Fujita, and M. Kada, Proc. Electron. Compon. Conf. (1998). https://doi.org/10.110 9/ECTC.1998.678743.

56. V. Solberg, in Proceedings of the Electronic Packaging Technology Conference, EPTC, 2000. https://doi.org/10.1109/ EPTC.2000.906342. 
57. C. Shen, Z. Hai, C. Zhao, J. Zhang, J.L. Evans, M.J. Bozack, and J.C. Suhling, Materials (2017). https://doi.org/10.3390/ ma10050451.

58. C.G. Kuo, S.M.L. Sastry, and K.L. Jerina, Metall. Mater. Trans. A (1995). https://doi.org/10.1007/BF02669454.

59. G.B. Kromann, D. Gerke, and W. Huang, in 1995 Proceedings. 45th Electronic Components and Technology Conference, 1995 , p. 1.

60. R. Guha, D. Humphrey, K. Prodromides, T. Burnette, T. Koschmieder, M. Osterman, H. Qi, J. Kennedy, J. Veum, SAE Tech. Pap. 2002-01-3011, 2002, 2002.

61. M. Meilunas, A. Primavera, and S.S.O.S. Dunford, in Proc. IPC Annu., 2002.

62. S. Chaparala, J.M. Pitarresi, and M. Meilunas, Am. Soc. Mech. Eng. Electron. Photon. Packag. (2006). https://doi.org/ 10.1115/IMECE2006-13376.

63. W. Engelmaier, 'IPC Guidel. IPC-SM-785, 1992.

64. IPC-9701, Assoc. Connect. Electron. Ind., 2002.

65. IPC-9701A, Assoc. Connect. Electron. Ind., 2006

66. JESD22-B111, JEDEC Solid State Technol. Assoc, 2003.

67. IPC/JEDEC-9702, Assoc. Connect. Electron. Ind., 2004.

68. J.S. Hwang, Solder paste in electronics packaging, Illustrate., Van Nostrand Reinhold, 1989, p. 456.

69. P.V. Bolotoff, Alasir Enterprises, 1999-2019, 2010. [Online]. Available: http://alasir.com/reference/solder_alloys/. Accessed 30 Apr 2020.

70. Topline, 'BGA', 2020. [Online]. Available: https://www.topli ne.tv/SMD vrs_NSMD.html. Accessed $20 \mathrm{Feb} 2019$.

71. C.S. Lau, M.Z. Abdullah, and F.C. Ani, IEEE Trans. Compon. Packag. Manuf. Technol. (2012). https://doi.org/10.110 9/TCPMT.2012.2213341.

72. B.A. Zahn, Proc. Electron. Compon. Conf. (2002). https://doi. org/10.1109/ectc.2002.1008301.

73. T.T. Nguyen, D. Lee, J.B. Kwak, and S. Park, Microelectron. Reliab. (2010). https://doi.org/10.1016/j.microrel.2010.04.00 3.

74. X. Long, Y. Liu, Y. Yao, F. Jia, C. Zhou, Y. Fu, and Y. Wu, AIP Adv. (2018). https://doi.org/10.1063/1.5044446.

75. H. Beyer, V. Sivasubramaniam, M. Bayer, and S. Hartmann, in CIPS 2016 -9th International Conference on Integrated Power Electronics Systems, 2019.

76. J. Eckermann, S. Mehmood, H.M. Davies, N.P. Lavery, S.G. Brown, J. Sienz, A. Jones, and P. Sommerfeld, Microelectron. Reliab. (2014). https://doi.org/10.1016/j.microrel.2014. 02.017 .

77. S. Stoyanov, C. Bailey, and M. Desmulliez, Solder. Surf. Mt. Technol. (2009). https://doi.org/10.1108/0954091091092826 5 .
78. S. Wiese, A. Schubert, H. Walter, R. Dukek, F. Feustel, E. Meusel, and B. Michel, Proc. Electron. Compon. Conf. (2001). https://doi.org/10.1109/ectc.2001.927900.

79. P.T. Vianco, in ASM Int., 2005.

80. Q. Wang, R. Wayne Johnson, H. Ma, W.F. Gale, and D. Lindahl, in IPC - Electronic Circuits World Convention, Printed Circuits Expo, Apex, and the Designers Summit 2005, ECWC 10: The Perfect Fit, 2005.

81. T.Y. Pan, J. Electron. Packag. Trans. ASME 113, 8 (1991). h ttps://doi.org/10.1115/1.2905373.

82. X.Q. Shi, Z.P. Wang, Q.J. Yang, and H.L.J. Pang, J. Eng. Mater. Technol. Trans. ASME (2003). https://doi.org/10.111 5/1.1525254.

83. B.P. Kashyap and G.S. Murty, Mater. Sci. Eng. (1981). h ttps://doi.org/10.1016/0025-5416(81)90179-8.

84. H. Ma, J.C. Suhling, P. Lall, and M.J. Bozack, Proc. Electron. Compon. Conf. (2006). https://doi.org/10.1109/ECTC.2 006.1645757.

85. H. Ma, J.C. Suhling, Y. Zhang, P. Lall, and M.J. Bozack, Proc. Electron. Compon. Conf. (2007). https://doi.org/10.110 9/ECTC.2007.373867.

86. J.B. Libot, J. Alexis, O. Dalverny, L. Arnaud, P. Milesi, and F. Dulondel, Microelectron. Reliab. (2018). https://doi.org/10 1016/j.microrel.2018.02.009.

87. J.B. Libot, F. Dulondel, P. Milesi, J. Alexis, L. Arnaud, and O. Dalverny, Proc. Electron. Compon. Conf. (2018). https://d oi.org/10.1109/ECTC.2018.00116.

88. D.M. Pierce, S.D. Sheppard, P.T. Vianco, J.A. Regent, and J.M. Grazier, J. Electron. Packag. (2008). https://doi.org/10. $1115 / 1.2837515$

89. M. Schäfer, O. Schilling, C. Yue, and T. Kashko, in PCIM Europe Conference Proceedings, 2014.

90. T. An, C. Fang, F. Qin, H. Li, T. Tang, and P. Chen, Microelectron. Reliab. (2018). https://doi.org/10.1016/j.microrel. 2018.10.003.

91. M.C. Hsieh and S.L. Tzeng, Proc. Electron. Packag. Technol. Conf. EPTC (2014). https://doi.org/10.1109/ICEPT.2014.692 2704.

92. E. George, D. Das, M. Osterman, and M. Pecht, IEEE Trans. Device Mater. Reliab. (2011). https://doi.org/10.1109/TDMR. 2011.2134100.

93. A. Syed, in 2004 Proceedings. 54th Electronic Components and Technology Conference (IEEE Cat. No. 04CH37546), No. February, p. 737, 2016, https://doi.org/10.1109/ectc.2004.13 19419.

Publisher's Note Springer Nature remains neutral with regard to jurisdictional claims in published maps and institutional affiliations. 